\title{
Determination of $\boldsymbol{N}$-linked glycosylation in viral glycoproteins by negative ion mass spectrometry and ion mobility
}

\author{
David Bitto $^{a}$, David J. Harvey ${ }^{b}$, Steinar Halldorsson ${ }^{b}$, Katie J. Doores ${ }^{c}$, Laura K. Pritchard ${ }^{b}$, \\ Juha T. Huiskonen ${ }^{\mathrm{b}}$, Thomas A. Bowden ${ }^{\mathrm{b}}$, and Max Crispin ${ }^{\mathrm{a},{ }^{*}}$ \\ aDivision of Structural Biology, Wellcome Trust Centre for Human Genetics, University of Oxford, \\ Oxford, UK \\ bOxford Glycobiology Institute, Department of Biochemistry, University of Oxford, Oxford, UK \\ 'King's College London, School of Medicine at Guy's, King's and St Thomas' Hospitals, Guy's \\ Hospital, Great Maze Pond, London, UK
}

\section{Summary}

Glycan analysis of virion-derived glycoproteins is challenging due to the difficulties in glycoprotein isolation and low sample abundance. Here, we describe how ion mobility mass spectrometry can be used to obtain spectra from virion samples. We also describe how negative ion fragmentation of glycans can be used to probe structural features of virion glycans.

\section{Keywords}

Virus; glycosylation; structure; mass spectrometry; glycoprotein

\section{Introduction}

Membrane-embedded glycoproteins that extend from the virion surface are key determinants of host cell tropism and pathobiology (1). An understanding of the structure of such viral glycoproteins is key for revealing mechanisms of host infection and molecular targets of the immune response.

Biophysical tools such as macromolecular crystallography and electron microscopy are important for studying viral glycoprotein functionality at the amino-acid level (2). However, due to the inherent flexibility and heterogeneity of glycans, these techniques are often unsuitable for defining glycan structure and composition. As a result, glycans are often removed prior to structural analysis (3) and as such, their structure and function remain poorly understood with respect to protein-counterparts.

Virion-presented $N$-linked glycosylation is known to play multiple roles in the virus-life cycle. Whilst often a basic requirement for host-directed protein-biosynthesis and -folding, more diverse roles have been identified in processes such as host cell infection and immune evasion. For example, the glycoproteins from a number of viruses, including flaviviruses,

\footnotetext{
*To whom correspondence should be addressed, Max Crispin, Email: max.crispin@bioch.ox.ac.uk, Tel: +44(0)1865 285445.
} 
alphaviruses, and phleboviruses, have been observed to display high-mannose type glycans, which act as attachment receptors for host C-type lectins, such as DC-SIGN (4). $N$-linked glycans are also known to play a role in viral immune evasion. For example, in the case of HIV-1, where glycosylation content accounts for around $50 \%$ of the molecular mass of the gp120 viral attachment protein, the high-mannose content of the 'glycan shield' creates an immunologically 'non-self' mannose patch (5-7). The recent discovery of a library of monoclonal antibodies that target both these glycan patches and mixed protein-glycan epitopes (8-13) provides hope for the future development of an anti-glycan inducing vaccine (14-16).

The extent by which host-derived biosynthetic enzymes influence viral glycan composition is fundamentally dependent upon the extraneous protein environment during glycoprotein biosynthesis and folding (17). As such, accurate glycan structure and compositional analysis necessitates a sample most closely resembling that produced in infected tissue. Here, using Uukuniemi phlebovirus as a model system, we present a robust ion mobility mass spectrometry-based methodology for compositional and structural analysis of $N$-linked glycans derived from intact virions produced in cell culture (Figure 1), the results of which have recently been reported (18). This methodology relies upon the production of viral particles to a purity sufficient for isolation by SDS-PAGE analysis. To confirm virion integrity, electron microscopy is utilized as a validation tool, prior to mass spectrometric analysis. We anticipate that the sensitivity of this approach will enable study of low-titre and difficult to isolate viruses, previously not tractable for glycan analysis.

\subsection{Mass Spectrometry}

1.1.1 lonization-Mass spectra of the $\mathrm{N}$-glycans can be obtained using either matrixassisted laser desorption/ionization (MALDI) or electrospray ionization (ESI). MALDI in positive ion mode is most appropriate for obtaining profiles of neutral glycans because of the production of singly charged $[\mathrm{M}+\mathrm{Na}]^{+}$ions. Sialylated glycans, however, are relatively unstable and readily eliminate sialic acid as the result of the mobile nature of the carboxyl proton. This decomposition can be prevented by derivatization of the carboxyl group by esterification $(19,20)$ or amide formation (21). Methyl esters can conveniently be prepared by reaction of the sodium salts of the sialic acids with methyl iodide (19). A more useful reaction is that with methanol catalysed by 4-(4,6-dimethoxy-1,3,5-triazin-2-yl)-4methylmorpholinium chloride (DMT-MM). This reaction produces methyl esters from a26 -linked sialic acids and lactones from a2-3-linked acids (20). The mass difference between these products is 32 units allowing the linkage of the sialic acids to be determined directly by mass measurement. The same catalyst can be used to synthesise amides.

ESI has the disadvantage of producing fragmentation in the ion source of the mass spectrometer and production of ions in several charge states, often leading to several ions from each glycan. Hence the advantage of MALDI for glycan profiling. In addition, several adducts are sometimes produced, particularly in negative ion mode, further complicating the spectra. This situation, however, can be improved by adding various salts to direct adduct formation in only one direction as described below 
1.1.2. Fragmentation-Carbohydrates fragment predominantly by two mechanisms: glycosidic cleavages between the sugar rings and cross-ring cleavages formed by cleavage of two bonds within the rings. Glycosidic cleavages give information on constituent monosaccharide sequences whereas the cross-ring cleavages yield information on the positions of attachment of the various constituent sugars. Although fragmentation in positive ion mode has been the favoured method in the past, negative ion fragmentation has been shown to produce simpler but much more structurally informative spectra (22-25) and is used here. Main disadvantages of positive ion spectra are the production of glycosidic fragments by loss of residues from several sites and the generally low abundance of crossring cleavage ions. Negative ion spectra, on the other hand contain abundant cross-ring cleavage products as the result of proton loss from specific hydroxyl groups. They enable structural features such as the branching pattern of the glycan, the location of fucose, the presence of bisects and the number of isomers to be determined directly; features that are difficult to determine by positive ion fragmentation. Some typical spectra are shown in Figures 2 and 3 and details of the diagnostic ions are given in section 3.5.3.1.

In negative ion mode, carbohydrates naturally form $[\mathrm{M}-\mathrm{H}]^{-}$ions or $\left[\mathrm{M}-\mathrm{H}_{\mathrm{n}}\right]^{\mathrm{n}-}$ ions if several acid groups are present. $[\mathrm{M}-\mathrm{H}]^{-}$ions are relatively unstable leading to extensive fragment ion production. However, neutral glycans can also be made to form stable $[\mathrm{M}+\mathrm{X}]^{-}$ions where $\mathrm{X}$ is an anion such as a halogen, nitrate, phosphate or sulphate. Nitrate, chloride and phosphate adducts all fragment similarly by first eliminating the adduct together with a proton to leave what is essentially a $[\mathrm{M}-\mathrm{H}]^{-}$ion. Although nitrate adducts give the cleanest glycan profiles, samples from biological sources invariably contain phosphate and some chloride. Thus, for the present work, formation of $\left[\mathrm{M}+\mathrm{H}_{2} \mathrm{PO}_{4}\right]^{-}$ions is maximized by addition of ammonium phosphate to the sample solution. Sulfate and iodide adducts give very strong spectra but do not produce fragment ions. Fragmentation spectra of sialylated glycans are not as informative as those of the $\left[\mathrm{M}+\mathrm{H}_{2} \mathrm{PO}_{4}\right]^{-}$ions from the neutral glycans because of formation of $\left[\mathrm{M}-\mathrm{H}_{\mathrm{n}}\right]^{\mathrm{n}-}$ ions. These ions are formed by loss of protons from the sialic acids rather than the $\mathrm{OH}$ groups, thus inhibiting the formation of the main diagnostic ions that were present in the spectra of the neutral glycans. Derivatization, as described above, removes this problem.

The scheme that is universally used to name the fragment ions is that devised by Domon and Costello in 1988 (26). For ions with charge retention on the reducing end of the ion, glycosidic cleavage ions are labelled Y (cleavage on the non-reducing end of the linking oxygen) and $\mathrm{Z}$ with subscript numbers starting with 1 for the reducing terminal glycan as shown in Figure 4. Corresponding glycosidic cleavages with charge retention on the nonreducing end of the ion are labelled $\mathrm{B}$ and $\mathrm{C}$ with subscript numbers starting from the nonreducing end. Cross ring cleavages are $\mathrm{A}$ and $\mathrm{X}$ with preceding superscript numbers denoting which bonds are cleaved. Negative ion spectra tend to contain larger amounts of B, $\mathrm{C}$ and particularly A-type fragments. We have modified this system somewhat when discussing fragmentation of the reducing terminus. Here, under the Domon and Costello system, the subscript numbers change as the result of differing chain lengths. In order to avoid the subsequent confusion, $\mathrm{A}, \mathrm{B}$ and $\mathrm{C}$ ions are given the subscript $\mathrm{R}$ for cleavages at the reducing terminal GlcNAc, R-1 for the penultimate GlcNAc and R-2 for the branching 
mannose. Ions formed by a specific loss of the 3 -antenna and chitobiose core, i.e. they contain the intact 6-antenna and branching mannose are called D ions. A cross ring cleavage ion from the mannose residue in the 3-antenna containing carbons 1-4 and, consequently the chains linked to carbons 2 and 4 for in some triantennary glycans is referred to as an E-type ion. The $\mathrm{D}$ and $\mathrm{E}$ nomenclature is not part of the Domon and Costello system.

1.1.3. Ion mobility-Work reported in this paper uses the Waters Synapt G2 mass spectrometer which has a Q-Tof-type configuration with a travelling-wave ion mobility cell positioned between the quadrupole and the TOF analyser. A trap collision cell precedes the ion mobility cell and a second collision cell, known as the transfer cell follows it. For the work reported here, collision-induced decomposition (CID) is performed in the transfer cell. The ion mobility cell separates ions on the basis of charge and shape and is used in this work both to separate ions in different charge states and to remove contaminants $(27,28)$. Figure 5 a shows the ESI spectra of $\mathrm{N}$-glycans from UUKV. The spectrum is weak, as would be expected from the small amount of material available. Figure 6 shows a plot (Waters Driftscope) of ion mobility drift time against $\mathrm{m} / \mathrm{z}$ showing fractionation of the glycan ions according to charge. By selecting the regions highlighted in the figure, the profiles of glycans with one, two and three/four charges can be extracted and displayed as in panels c, d and e of Figure 5. Not only does this method allow ions in specific charge states to be extracted but much of the chemical noise is rejected giving clean spectra with good signal:noise ratios. Ion mobility can be used in the same way to clean fragment ions by removing those fragments produced by co-selected parent ions with equivalent $\mathrm{m} / \mathrm{z}$ values. A good example of this is the singly charged ion at $\mathrm{m} / \mathrm{z} 1007$ corresponding to $\mathrm{Man}_{3} \mathrm{GlcNAc}_{2}$ and the triply charged ion from $\mathrm{Gal}_{3} \mathrm{Man}_{3} \mathrm{GlcNAc}_{5} \mathrm{Fuc}_{1} \mathrm{Neu}_{5} \mathrm{Ac}_{3}$ both of which are commonly found in $\mathrm{N}$-glycan mixtures.

Negative ion fragmentation combined with ion mobility can be used to detect the presence of isomeric glycans. Such compounds cannot be separated by mass spectrometry alone but, frequently their negative ion fragmentation spectra contain ions of different mass. By plotting arrival time distributions of these fragments it can often be seen that there is a small separation between them confirming the presence of isomers. Another parameter that can be derived is the collisional cross section of the ions. This parameter is independent of the instrument used to record the cross section and can, thus, be used in databases in a similar way to the use of glucose units in HPLC.

\section{Materials}

1 BHK-21 cells (in this work provided by Dr. Anna Överby, Umeå, Sweden), cultured in Glasgow's Minimum Essential Medium (GMEM, Life technologies, UK), supplemented with 5\% v/v Fetal bovine serum, $20 \mathrm{mM}$ 4-(2Hydroxyethyl)piperazine-1-ethanesulfonic acid (HEPES) buffer and 10\% w/v Tryptose phosphate broth.

2 UUKV strain S23 (from Dr. Anna Överby, Umeå, Sweden) see (29).

3 Sterile phosphate buffered saline (PBS) and cell culture grade Trypsinethylenediaminetetraacetate (EDTA) solution. 
4 Three or more cell culture flasks, $175 \mathrm{~cm}^{2} /$ flask surface area with filter cap (Greiner Bio-One, UK). One flask is used for cell counting and culturing. The other flasks are used for virus production.

5 Cell counting chamber (e.g. Neubauer counting chamber).

$650 \mathrm{ml}$ Falcon tubes.

$7 \quad$ Sucrose.

8 Low speed centrifuge (e.g. Beckman Coulter (UK) Ltd, Allegra X-12A).

9 Ultracentrifuge (e.g. Beckman Coulter (UK) Ltd, Optima L-80 XP) and ultracentrifuge rotor with compatible buckets (Beckman Coulter (UK) Ltd, SW28 or SW32).

10 Disposable ultracentrifuge tubes compatible with the buckets used (e.g. thin-wall polyclear, from Seton Scientific, USA).

11 HEPES buffering agent, EDTA and sodium chloride powder.

$1250 \mathrm{ml}$ plastic syringe and $0.2 \mu \mathrm{m}$ Minisart plastic syringe filters (Sartorius Stedim, UK).

13 A plunge-freezing device (See Note 1).

14 Molybdenum grids with holey carbon film (Quantifoil, Microtools, Germany, see Note 1 for possible alternatives) and grid boxes (e.g. Ted Pella, USA) for storing grids in liquid nitrogen.

15 Positive and negative action tweezers (Electron Microscopy Sciences, USA, see Note 2).

16 Large tweezers for handling materials in liquid nitrogen.

17 A cryo grid box handling rod (e.g. Ted Pella, USA)

18 Liquid nitrogen storage dewars (e.g. Statebourne Cryogenics, UK).

19 Transfer dewars (e.g. Statebourne Cryogenics, UK).

20 Plastic 50-ml falcon tubes. For storage of grid boxes in liquid nitrogen, small holes ( $\sim 0.5 \mathrm{~cm}$ diameter) must be drilled into the caps and the tubes prior to use to avoid pressure building inside of the tubes due to boiling of liquid nitrogen.

21 Liquid nitrogen and liquid ethane.

22 Plasma cleaner (Harrick Plasma, USA).

23 Plastic Petri dish.

\footnotetext{
${ }^{1}$ The manually-operated plunge freezer device used in this protocol was custom-built in the Max Planck Institute for Biochemistry, Martinsried, Germany. Semi-automatic alternatives include, for example, those manufactured by FEI (Vitrobot; FEI, Netherlands) and Gatan (Cryo plunge 3; Gatan, USA). If one of the latter devices is used, the blotting protocols may need to be adjusted, and it is of advantage to keep the grids, once loaded with virus sample, in a humid atmosphere. Additionally, other EM grids (molybdenum or copper) may be purchased, such as holey carbon film C-flat grids (Protochips, USA), as long as they have a holey carbon film. ${ }^{2}$ Negative action tweezers can be modified to fit a custom-built plunge-freezer. If a commercial plunge-freezer is used, follow the manufacturer's guidance regarding which tweezers are most appropriate.
} 
24 Glass slides, and parafilm.

25 Blotting paper (Whatman, UK).

26 Preparation of concentrated UUKV, strain S23.

27 FEI F30 Polara electron microscope (FEI, Netherlands).

28 4-12\% Bis-Tris gradient gel.

29 2-Amino-2-(hydroxymethyl)-1,3-propanediol (Tris-base), Sodium dodecyl sulphate, Glycerol, Glycine to mix the following components: Non-reducing SDS sample buffer (187.5 mM Tris pH 6.8, 2\% w/v SDS, 33\% v/v glycerol), SDS running buffer (25 mM Tris, $192 \mathrm{mM}$ Glycine, 0.1\% w/v SDS, $\mathrm{pH}$ 8.5).

30 Precision Plus Protein Kaleidoscope Standards (Bio-Rad Laboratories Ltd, Hemel Hempstead, Herts, UK)

30 Sterile, disposable scalpel.

$31 \quad 1.5 \mathrm{ml}$ Eppendorf tubes.

32 Safestain (Life technologies, UK) for staining of protein bands on SDS gels.

33 Cell culture incubator at $37^{\circ} \mathrm{C}$ and $5 \% \mathrm{CO}_{2}$.

34 PCR tubes or equivalent for handling $\mu$ l quantities of solution.

35 Nafion membrane (Aldrich, Poole, UK)

36 Concentrated nitric acid.

$37250 \mathrm{ml}$ beaker (for preparing Nafion membranes).

$38 \quad 0.5 \mu \mathrm{l}-2 \mu \mathrm{l}$ and $2 \mu \mathrm{L}-20 \mu \mathrm{l}$ Gilson pipettes and tips.

$391 \mathrm{M}$ sodium hydroxide solution.

40 Dowex AG50W resin (Bio-Rad Laboratories Ltd, Hemel Hempstead, Herts, UK).

41 Vacuum rotary evaporator.

42 Dimethylsulfoxide (DMSO)

43 Methanol.

44 Methyl iodide.

45 4-(4,6-Dimethoxy-1,3,5-triazin-2-yl)-4-methylmorpholin-4-ium chloride (DMTMM) ( see Note 3 ).

46 Electric heating block or water bath.

47 Ammonium phosphate.

${ }^{3}$ DMT-MM can be purchased from Sigma-Aldrich (Product code 74104) or synthesed from $N$-methylmorpholine and 4-chloro-2,6dimethoxytriazine by the method described by Kunishima et al. (39). 
48 Waters Synapt G2 mass spectrometer (Waters Corp. Manchester, UK).

$49 \quad$ Nanospray capillaries (see Note 4).

50 2,5-Dihydroxybenzoic acid (DHB).

51 Acetonitrile, ethanol, acetone. About $1 \mathrm{ml}$ each for preparation of MALDI matrices.

52 2,4,6-trihydroxyacetophenone (THAP) and ammonium nitrate if negative ion MALDI is to be attempted..

53 Vacuum concentrator

54 Bench top incubator at $37^{\circ} \mathrm{C}$

55 Peptide- $N$-Glycosidase F (PNGase F), glycerol-free (New England Biolabs, Ipswich, MA, USA).

56 a2-3,6,8,9 Neuraminidase (New England Biolabs, Ipswich, MA, USA).

57 96-well multiscreen IP filter plate with $0.45 \mu \mathrm{m}$ pore size PVDF membrane (Merck Millipore, MA, USA).

58 96-well $2 \mathrm{ml}$ collection plate

58 96-well vacuum manifold assembly block and vacuum manifold pump.

\section{Methods}

\subsection{Virus production}

The UUKV production and purification protocol is similar to previously established methods $(30,31)$.

1. Prepare the following solutions:

20 mM HEPES, 100 mM NaCl, 2 mM EDTA (H20N100E2, see Note 5).

$20 \%$ sucrose in $20 \mathrm{mM}$ HEPES, $100 \mathrm{mM} \mathrm{NaCl}, 2 \mathrm{mM}$ EDTA.

Phosphate buffered saline (PBS), to be autoclaved.

Cool down the first two solutions to $4{ }^{\circ} \mathrm{C}$ and sterilize by filtration.

2. BHK-21 cells are propagated to $\sim 80-90 \%$ confluency in $175 \mathrm{~cm}^{2}$ cell culture flasks, using PBS for cell wash steps and Trypsin-EDTA solution for cell detachment, as required for cell passaging of adherent cells. The total volume of complete growth media used is $20 \mathrm{ml}$ per cell culture flask (see Note 6).

\footnotetext{
${ }^{4}$ Waters long thin wall capillaries (part No. M956232AD1 S) are satisfactory or capillaries can be made "in house".

5 Alternative buffers may be equally suitable as long as they contain $100 \mathrm{mM} \mathrm{NaCl}$ and are held at neutral pH (e.g. pH 7.2 to $\mathrm{pH} 7.5$ ). For example, as an alternative one may use $20 \mathrm{mM}$ Tris-buffer, $100 \mathrm{mM} \mathrm{NaCl} \mathrm{pH} \mathrm{7.4.} \mathrm{The} \mathrm{use} \mathrm{of} \mathrm{EDTA} \mathrm{in} \mathrm{resuspension} \mathrm{buffer} \mathrm{and}$ sucrose solution is not essential. If no EDTA is used in the virus resuspension buffer, it needs to be present in the SDS sample buffer ( 2mM EDTA), otherwise there will be aggregation in the wells of the SDS-gel.

${ }^{6}$ All the procedures that involve living cells and virus should be carried out in a standard class 2 biosafety cabinet.
} 
3. The amount of virus needed per flask is determined for a multiplicity of infection (MoI) of 0.1. To this end, determine the number of cells per flask by using a cell counting chamber. Scale the amount of virus according to the number of flasks used. Add a pre-determined volume of concentrated UUKV S23 preparation corresponding to a MoI of 0.1 into a sterile container (e.g. an empty cell culture flask) that contains a multiple of $20 \mathrm{ml}$ serum-free growth media (add some excess). Mix well by pipetting up and down.

4. Wash cells once with serum-free growth media. Add $20 \mathrm{ml}$ of UUKV inoculum to each flask.

5. Incubate flasks for $1 \mathrm{~h}$ at $37^{\circ} \mathrm{C}$ and $5 \% \mathrm{CO}_{2}$.

6. Remove virus inoculum, add $20 \mathrm{ml}$ of serum-free growth media, and incubate for two days, up to $48 \mathrm{~h}$ ( see Note 7 ) at $37^{\circ} \mathrm{C}$ and $5 \% \mathrm{CO}_{2}$.

7. Collect virus-containing cell supernatant in $50 \mathrm{ml} \mathrm{Falcon}$ tubes, cool to $4^{\circ} \mathrm{C}$, and centrifuge for 30 minutes at $3000 \mathrm{x} \mathrm{g}, 4^{\circ} \mathrm{C}$.

8. After centrifugation, pool virus-containing supernatant (e.g. in a sterile T175 flask).

9. Add viral supernatant into plastic ultracentrifuge tubes compatible with BeckmanCoulter SW32/28 centrifuge buckets and $2 \mathrm{ml}$ of $20 \%$ sucrose solution from the bottom of the tube (see Note 8 ).

10. Place the plastic ultracentrifuge tubes containing both the infectious supernatant and sucrose cushion into the ultracentrifuge buckets and centrifuge for 2 hours at $4^{\circ} \mathrm{C}$ and $100,000 \mathrm{xg}$.

11. After centrifugation, discard the supernatant, blot the excess of liquid with paper, and immediately add 100-300 $\mu \mathrm{l}$ cold H20N100E2 buffer to the virus pellet. Dissolve the pellet overnight at $4^{\circ} \mathrm{C}$ ( see Note 9).

12. Gently but fully resuspend the virus pellet by pipetting on ice. At this point, aliquots can be prepared and stored at $-80{ }^{\circ} \mathrm{C}$ for long term storage (see Note 10).

\subsection{Electron cryo-microscopy of UUKV preparations}

This section describes virus sample preparation for the qualitative assessment of native UUKV particles by electron cryo-microscopy. Alternatively, negative staining at room temperature microscopy can be used, although this method may be less suitable for assessing structural integrity of membraneous viruses in the unfixed state, because the stain (e.g. uranylacetate) would compromise the structural integrity of the virions. Electron cryo-

\footnotetext{
${ }^{7}$ Infectious supernatant can also be harvested before $48 \mathrm{~h}$ incubation, usually once the cells start detaching, which may happen after $\sim 43 \mathrm{~h}$ of incubation already.

${ }^{8}$ Sucrose may be added using $1 \mathrm{ml}$ filter tips or serological pipettes. Care needs to be taken not to overfill the tubes before adding the cushion from the bottom. Ideally, about $30 \mathrm{ml}$ of infectious supernatant can be added first and then $2 \mathrm{ml}$ of sucrose solution. Remaining supernatant may then be added carefully from the top to fill the tube to the maximal recommended volume.

${ }^{9}$ For the overnight incubation step, the ultracentrifuge tubes may be transferred to $50 \mathrm{ml}$ plastic falcon tubes, sealed and stored in a fridge or cold room, to avoid incubation of open containers on ice. Virus pellets should be dissolved for at least two hours.

${ }^{10}$ The amount of viral glycoprotein present in the virus preparation may be estimated by SDS-PAGE analysis using different volumes (e.g. 5-20 $\mu \mathrm{l}$ of virus preparation), using a reference protein with known concentration. Viral glycoprotein concentrations of Uukuniemi virus pellets are usually in the lower $\mu \mathrm{M}$ range.
} 
microscopy acquisition parameters used for UUKV are given below, but for a detailed description of sample mounting and image acquisition using an FEI Polara electron microscope (as used here), please refer to (32). A lower end electron microscope is suitable as long as the sample holder of the microscope can be used at liquid nitrogen temperature and the viral glycoprotein spikes and lipid bilayers are visible in the acquired projection images.

1. Cool the plunge-freezer (see Note 1) with liquid nitrogen (allow 20 minutes for cooling to liquid nitrogen temperature).

2. Wrap a glass slide in parafilm and place electron microscopy grids onto the slide, with the carbon film facing upwards.

3. Place the slide into the plasma cleaner chamber under vacuum for at least one minute. Perform glow discharge, which renders the carbon film of the copper grids hydrophilic, according to the manufacturer's instructions (see Note 11). With the Harrick plasma cleaner, the carbon-coated copper grids are glow-discharged for 20 seconds at the highest intensity. After glow discharge, store the slide with the grids in a plastic Petri dish, to prevent contact with dust

4. Add liquid ethane to the dedicated liquid ethane cup.

5. Add a few hundred $\mu \mathrm{l}$ of neutral $\mathrm{pH}$ buffer (e.g. H20N100) on top of a strip of parafilm.

6. Select a glow-discharged grid by using inverted tweezers. Add virus solution ( $3 \mu \mathrm{l}$ of virus preparation with a glycoprotein concentration in the lower $\mu \mathrm{M}$ range) onto the carbon coated side of the grid. Wash the carbon coated side facing the drop for 10 to 20 seconds against wash buffer (e.g. H20N100) to remove residual sucrose. Remove the grid sideways from the buffer too keep the liquid on the grid (33).

7. Mount tweezers onto the plunge freezing device and blot the liquid away with filter paper from the uncoated side of the grid, until the liquid stops spreading on the paper (typically for 2-4 seconds). As soon as the liquid stops spreading, release the tweezers from the plunge-freezing rod to allow rapid immersion of the grid in liquid ethane for vitrification. Once the grid is frozen, it has to be kept at liquid nitrogen temperature. Unmount the tweezers from the rod, transfer to a grid box in liquid nitrogen, close the grid box lid using the grid box tool, and store in liquid nitrogen until further use.

8. Assess the UUKV preparation in any electron microscope equipped for analysis of vitrified specimens at liquid nitrogen temperatures. For simple projection image acquisition on the FEI Tecnai Polara, we acquired images at $-5 \mu \mathrm{m}$ defocus, $300 \mathrm{kV}$, and a nominal magnification of 59000x (75000x calibrated magnification), leading to a calibrated pixel size of $2 \AA /$ pixel. The images were recorded with a charge-

\footnotetext{
${ }^{11}$ Depending on the exact device available, the glow discharging procedure may be different. In principle, after a vacuum has been pumped, a small amount of air is allowed to flow back into the chamber, to allow plasma formation, which in turn will ionize the carbon film, rendering it more hydrophilic.
} 
coupled device (CCD) camera (Ultrascan 4000, Gatan, USA), in low dose mode, using 20 electrons $/ \AA^{2}$ (Figure 1).

\subsection{SDS-PAGE of UUKV preparation and gel band excision}

For a reproducible MS analysis of glycoprotein-derived $\mathrm{N}$-glycans, glycoprotein bands on SDS gels need to contain protein in the range of several $\mu \mathrm{g}$. In a previous study, as much as $\sim 4 \mu \mathrm{g}$ per viral glycoprotein were sufficient to generate reproducible MS data (34).

1. For UUKV, a second pelleting step over a sucrose cushion that increases the virus concentration, is needed. To this end, dilute appropriate amounts of concentrated UUKV preparations from the first pelleting step in serum-free GMEM, and repellet over a sucrose cushion in a single ultracentrifuge tube.

2. Mix the virus sample with non-reducing SDS sample buffer at room temperature and load onto an SDS gel. Additionally, load $10 \mu \mathrm{l}$ of Precision Plus Protein Kaleidoscope Standards.

3. Run the SDS gel for 1 hour at $180 \mathrm{~V}$.

4. Stain gels with Safestain and de-stain with de-ionized water.

5. Cut out bands corresponding to viral glycoproteins with a sterile scalpel on a clean surface (to avoid cross-contamination). Cut bands into pieces approximately $1 \times 1$ $\mathrm{mm}^{2}$ and freeze at $-20{ }^{\circ} \mathrm{C}$ until further use.

\subsection{Release of glycans from within the SDS gel bands}

1. Wash the gel pieces alternately with $1 \mathrm{ml}$ of acetonitrile and de-ionized water. Perform five washing steps in total, starting and finishing with acetonitrile. On the final wash leave the gel pieces in acetonitrile for $10 \mathrm{~min}$ to allow dehydration of the gel. Discard the acetonitrile wash and dry gel bands fully in the vacuum concentrator.

2. Dilute PNGase F 1:100 in de-ionized water and add $50 \mu$ to each sample. Allow the gel pieces to rehydrate fully, adding more PNGase F solution as necessary so the gel pieces are just covered.

3. Incubate samples for 16 hours at $37^{\circ} \mathrm{C}$.

4. Transfer reaction supernatant to clean $1.5 \mathrm{ml}$ Eppendorf. Wash gel pieces with 100 $\mu \mathrm{l}$ deionised water, each time vortexing well, and transfer washes to the stored supernatant.

5. Dry eluted glycans in the vacuum concentrator.

\subsection{Analysis by mass spectrometry / Sample preparation}

Sialylated glycans can be profiled directly by negative ion electrospray mass spectrometry where they will produce singly or multiply charged ions depending on the number of sialic acids but fragmentation will provide little detailed structural information. Alternatively, glycan profiles can be obtained by MALDI after preparation of methyl esters or amides because underivatized sialylated glycans will eliminate much sialic acid under these 
conditions. Permethylation is not advised because such compounds do not give negative ion fragmentation spectra. A good compromise is to record the spectra by electrospray to obtain molecular weight and composition information together with information on the nature and linkage of the sialic acid, then desialylate and repeat the acquisition. The spectra of the resulting desialylated glycans will provide the necessary structural information enabling the structures of the sialylated glycans to be deduced. No useful structural information is gained by reducing-terminal derivatization; in most cases, such derivatization has a detrimental effect on fragmentation. Glycans derivitised with 2-aminobenzoic acid, in particular, produce little useful information because the negative charged is localized on the derivative rather than on the glycan.

1. Glycan samples should be dissolved in water at approximately $1 \mu \mathrm{g} / \mu \mathrm{l}$.

2. Prepare Nafion 117 membrane as described by Bornsen et al. (35). (see Notes 12 and ${ }^{13}$ )

3. Cut the membrane into approximately $2 \times 2 \mathrm{~cm}$ squares and float one of these in a small container of water. A Petri dish is a suitable container.

4. Place $1 \mu \mathrm{l}$ samples of the glycan solutions on the surface of the membrane, cover the dish to limit evaporation and leave for about an hour (see Note 14).

5. Analyse the sample by MALDI or ESI as described below (Section 3.5.2).

If the glycans are found to be sialylated, the next step is either to remove the sialic acids and re-run the sample as neutral glycans as above or to derivatize the sialic acid moiety by forming methyl esters or amides to convert them to neutral compounds.

\subsubsection{Desialylation}

1. Clean $1 \mu \mathrm{l}$ of the original glycan solution with the Nafion membrane, as above

2. In an Eppendorf tube, add $1 \mu \mathrm{l}$ of a non-linkage-specific neuraminidase to the glycans and make up to a total of $10 \mu \mathrm{l}$ with de-ionized water.

3. Incubate for 16 hours at $37^{\circ} \mathrm{C}$.

4. Purify the glycans by applying them to a PVDF protein-binding membrane attached to a vacuum manifold: first activate the membrane with ethanol and wash with water; apply the sample and leave for 30 min; elute with water.

5. Dry glycans using a vacuum concentrator

\footnotetext{
${ }^{12}$ Cleaning the sample with a Nafion membrane is only one of several methods that could be adopted. Others include the use of porous graphatized carbon (PGC) (40) or cellulose (41).

${ }^{13}$ Nafion acts as a dialysis membrane allowing ions from salts etc. to diffuse into the water. It also has the ability to adsorb hydrophobic compounds; thus it is not appropriate for cleaning glycans that have been derivatized with e.g. with 2-aminobenzamide (2-AB).

${ }^{14}$ The length of time that the sample should remain on the membrane will depend on the amount of contaminants and should be determined by trial and error. Heavily contaminated samples benefit from leaving for several hours e.g. overnight. If the sample contains glycerol (found in some PNGase F preparations, water will diffuse into the sample, causing swelling and the possibility of samples merging. Such PNGase F preparations should be avoided.
} 


\subsubsection{Methyl ester formation}

\subsubsection{Use of methyl iodide (19)}

1. Prepare a small column of about $1 \mu \mathrm{l}$ of Dowex AG50W resin (Bio-Rad Laboratories Ltd, Hemel Hempstead, Herts, UK), wash with 1 molar sodium hydroxide solution $(1 \mathrm{ml})$ followed by an equivalent amount of water.

2. Clean a $1 \mu \mathrm{l}$ sample of the original glycan solution with Nafion as above.

3. Dilute the sample with about $10 \mu \mathrm{l}$ of water and apply to the column.

4. Elute with water $(500 \mu \mathrm{l})$ into a small Eppendorf tube.

5. Evaporate to dryness with a rotary evaporator.

6. Wash the sides of the tube with a further $100 \mu \mathrm{l}$ of water to concentrate the sample at the bottom of the tube and again evaporate to dryness.

7. Dissolve the sample in $d r y$ dimethylsulfoxide (DMSO, $1 \mu \mathrm{l}$ ) (see Note 15).

8. Add methyl iodide ( $1 \mathrm{ml}$, see Note 16$)$ and allow the mixture to stand for $2 \mathrm{~h}$ at room temperature.

9. Add a further $5 \mu \mathrm{l}$ of DMSO and evaporate the methyl iodide with a stream of nitrogen.

10. Evaporate to dryness with a rotary evaporator. The sample can now be re-dissolved in water and analysed as above.

11. If MALDI is used for analysis, $1 \mu \mathrm{l}$ aliquots of the DMSO solution can be spotted directly onto the MALDI target and allowed to dry (see Note 17).

\subsubsection{Use of methanol and DMT-MM (20) (see Note 3)}

1. Evaporate the cleaned glycan sample to dryness.

2. Add methanol (10 $\mu \mathrm{l})$ and $1 \mu \mathrm{l}$ of a methanolic solution (0.1 M) of DMT-MM (see Note 18).

3. Incubate at about $80^{\circ} \mathrm{C}$ for 1 hour

4. Evaporate to dryness and analyse by MALDI or ESI.

3.5.3. Acquisition of mass spectra data-Samples can be ionized either by ESI or by MALDI using a mass spectrometer such as the Waters Synapt G2 fitted with a MALDI ion source or with a MALDI-TOF instrument. Although it would be possible to analyse the samples by directly coupled HPLC-MS, the procedure reported here is specifically designed for clean-up of the samples by ion mobility.

\footnotetext{
15 DMSO can be dried with ( $4 \AA$, 14 x 30 mesh) molecular sieve.

16 Methyl iodide is toxic; consequently these steps should be performed in a fume hood.

17 DMSO has a low volatility and drying may take several hours.

${ }^{18}$ DMT-MM solutions in methanol are relatively unstable and must be made up immediately before use. Alternatively, a small crystal of DMT-MM can be adde to the methanolic glycan solution.
} 


\subsubsection{ESI}

1. Remove the sample from the Nafion membrane (from Section X.1.4) with a $2 \mu \mathrm{l}$ pipette and place into a PCR tube (or small equivalent).

2. Add $3 \mu \mathrm{l}$ water, $4 \mu \mathrm{l}$ methanol and $1 \mu \mathrm{l}$ of $0.05 \mathrm{M}$ ammonium phosphate (see Note 19).

3. Spin at $10,000 \mathrm{x}$ g for $1 \mathrm{~min}$. to sediment any particulates.

4. Transfer the sample to a nanospray capillary (see Note 4).

5. Spray into the mass spectrometer (a Waters Synapt G2 instrument is used in our work and settings refer to this instrument). Suitable parameters are: Capillary potential, $1.1 \mathrm{kV}$; Ion source temperature, $80^{\circ} \mathrm{C}$; Cone voltage $100 \mathrm{~V}$. These parameters may be altered depending on the sample.

6. Record the mass spectrum with the mobility cell switched on.

7. Record CID spectra for target ions as described below.

\subsubsection{MALDI ionization}

1. Remove the sample from the Nafion membrane with a $2 \mu$ pipette and place on the MALDI target plate.

2. For positive ion spectra, add $1 \mu$ of a solution of 2,5-dihydroxybenzoic acid (DHB, $10 \mathrm{mg}$ DHB in $1 \mathrm{ml}$ acetonitrile, see Note 20) and allow to dry under ambient conditions.

3. Re-dissolve in a minimum amount of ethanol (about $0.2 \mu \mathrm{l}$ ) and allow to dry (see Note 21).

4. For production of negative ion MALDI spectra, use an equivalent amount of 2,4,6trihydroxyacetophenone (THAP, in acetone) as the matrix and add $0.5 \mu \mathrm{l}$ of $0.5 \mathrm{M}$ ammonium nitrate (36). Allow to dry. Ethanol recrystallization is not needed because of the smaller crystals produced by THAP.

5. Introduce the target into the mass spectrometer and ionize with the minimum laser power that is consistent with sufficient signal strength.

\subsubsection{Acquisition of ion mobility data}

1. Set up the Synapt instrument for either ESI or MALDI ionization as above.

2. In ion mobility mode mode, set the ion mobility wave velocity to $450 \mathrm{~m} / \mathrm{sec}$ and the wave height to $40 \mathrm{~V}$.

3. Record the spectrum over the mass range $\mathrm{m} / \mathrm{z} 50-3500$.

\footnotetext{
${ }^{19}$ Other ammonium salts could be used at this stage to form the corresponding $[\mathrm{M}+\mathrm{X}]^{-}$ions.

20 Many other matrices have been reported for analysis of glycans (42) but DHB is the most widely used.

${ }^{21}$ DHB typically dries to give a target containing large crystals of DHB that point from the perifery of the target towards the center. The purpose of the ethanol is to produce a more uniform target with smaller crystals.
} 


\subsubsection{Acquisition of fragmentation data by collision-induced sissociation (CID)}

1. Set up the Synapt instrument in IMS mode for either ESI or MALDI ionization as above.

2. Record CID spectra for target ions in the transfer cell (see Note 22), accumulating the signal until a satisfactory signal:noise ratio is obtained (see Note 23). The voltage on the collision cell should be set to be appropriate to the $\mathrm{m} / \mathrm{z}$ value of the ions being fragmented using the information in Figure 7 (see Note 24). Spectra are interpreted as described in section X.3.1.

\subsubsection{Extraction of glycan ions using ion mobility}

1. Open the mass spectral file with DriftScope.

2. Select the ions of interest (click the "+" button followed by one of the blue symbols) (see Note 25).

3. Export the selected region to MassLynx (Use "File", "Export to MassLynx", "Retain drift time"). DriftScope appends concecutive numbers to the file name to identify the selected region.

4. Open the selected file in MassLynx, Chromatogram window and drag with the right mouse button across the display to show the mass spectrum in the spectrum window.

5. Dragging across selected ions or groups of ions (usually isotope peaks) with the right mouse button in the spectrum window displays the ion mobility data for the selected ions in the chromatogram window. These profiles should be roughly Gaussian for single components but may assymetric if isomers or conformers are present ( see Note 26)

6. CID spectra are best opened in DriftScope and the ions of interested selected as above (see Note 27).

\subsubsection{Interpretation of negative ion CID data of neutral ions (phosphate adducts, singly charged ions, with reference to Figure 2) (see Note 28)}

1. Locate the ${ }^{2,4} A_{R}, B_{R-1}$ and ${ }^{2,4} A_{R-1}$ ions (see Note 29 ).

\footnotetext{
${ }^{22}$ Fragment ions from the transfer cell all have the same mobility and are displayed vertically in a drift time (x axis): $\mathrm{m} / \mathrm{z}$ plot and easily separated from contaminating ions. Fragmentation can also be performed in the trap cell (before fragmentation) allowing mobility data to be collected from each fragment.

${ }^{23}$ For complicated samples, there is a balance between the number of spectra that can be recorded before the sample is exhausted and the signal:noise ratio. Selected ions can be targetted, if know, or if not, a good strategy is to target the abundant ions first as these will require less time for spectral acquisition allowing the maximum number of glycans to be fragmented before the sample is exhausted. ${ }^{24}$ The voltage on the collision cell should not be allowed to rise more than about $30 \mathrm{~V}$ above the recommended value in order to prevent the spectrum changing to one in which most diagnostic ions are missing (43).

${ }^{25}$ Ion selection buttons in DriftScope: The square highlights a rectangular region by dragging the mouse. The triangle extracts a triangular section. The circle allows the user to draw around the region of interest and the half-filled square is used to highlight a region by clicking at various points around the region of interest (double click to close the selected region).

26 Isomers and conformers can usually be differentiated by plotting corresponding mobilograms of fragment ions. If these have the same profile as that of the molecular ion, assymetry is probably due to conformers. If not, isomers are present.

${ }^{27}$ Any ion that falls within the window used by the quadrupole will produce fragments. With mixtures, it is often the case that several ions can be selected and each will produce fragments. See the example of $m / z 1007$ discussed above.
} 
2. Use Table 1 to derermine which adduct is present and, hence, the molecular weight of the glycan.

3. From the molecular weight, determine the isobaric monosaccharide content (see Notes 30 and ${ }^{31}$ ).

4. The mass difference between the molecular ion and the ${ }^{2,4} \mathrm{~A}_{\mathrm{R}}$ ion (see Table 1 , phosphate adducts) shows the presence or absence of fucose at the 6-position of the reducing terminal GlcNAc. Absence of the ${ }^{2,4} \mathrm{~A}_{\mathrm{R}}$ ion indicates substitution (fucose) at the 3-position of this GlcNAc.

5. Residues at the non-reducing terminus are identified by the masses of the $\mathrm{C}_{1}$ fragments listed in Table 3.

6. The composition of the 6-antenna is determined by the masses of the $\mathrm{D}$, $\mathrm{D}-18,{ }^{0,3} \mathrm{~A}_{\mathrm{R}-2}$ and ${ }^{0,4} \mathrm{~A}_{\mathrm{R}-2}$ ions (Table 4).

7. The branching pattern of the triantennary glycans can be determined by the presence of the ions listed in Table 5 (37) (see Figure 2).

8. The antenna composition is specified by the prominent cross-ring cleavage ion, (monosaccharides) $+\mathrm{CH}=\mathrm{CH}-0^{-}$ions listed in Table 6.

9. The presence of bisecting GlcNAc is revealed by the absence of a D ion and the presence of a prominent D-221 ion (loss of the bisecting GlcNAc) with masses as for the D-18 ions in Table 3 (Figure 2c).

10. Sialylated glycans (Neu5Ac) produce a prominent $B_{1}$ ion at $\mathrm{m} / \mathrm{z} 290$ (Figure $3 a, b, c)$. An additional ion of $10-15 \%$ relative abundance at $\mathrm{m} / \mathrm{z} 306$ indicates that

\footnotetext{
${ }^{28}$ With ammonium phosphate added to the ESI solvent, most adducts should be phosphate (addition of 96.969 mass units). However, there is the possibility that sufficient chloride is present to produce additional chloride adducts (addition of 34.969 units $\left({ }^{35} \mathrm{Cl}\right.$ isotope)). Thus, it is important to determine which adduct is present. Chloride adducts can often be identified by the presence of the ${ }^{35} \mathrm{Cl}$ and ${ }^{37} \mathrm{Cl}$ chloride isotopes. Negative ion MALDI spectra with ammoniun nitrate added to the matrix will, of course, produce nitrate adducts (addition of 61.989 units). Positive ion MALDI adducts are invariably sodium (22.989 units).

${ }^{29}$ The $\mathrm{B}_{\mathrm{R}-1}$ ion is 60 mass units less in mass than the ${ }^{2,4} \mathrm{AR}$ ion and the ${ }^{2,4} \mathrm{~A}_{\mathrm{R}-1}$ ion is 203 mass units lower if the penultimate GlcNAc contains no fucose, or 349 units lower if it contains a single fucose.

${ }^{30}$ The isobaric monosaccharide content is the number of hexose, HexNAc residues etc. The mass of the resulting ion is given by adding the residue masses of the monosaccharides (listed in Table 2), the mass of the adduct and the mass of one molecule of water (18.01). A spread sheet, a home-constructed software program or the use of an internet-available program such as GlycoMod (44) or that in GlycoWorkbench (http://glycomics.ccrc.uga.edu/eurocarb/gwb/home.action) can be used to obtain the composition from the measured mass. Unfortunately, the GlycoWorkbench algorithm does not work in negative ion mode but compositions can be obtained by using a mass corresponding to the experimentally measused mass, by subtraction of the mass of the adduct minus 1 (i.e. the mass of the $[\mathrm{M}+1]^{+}$ion) from that of the measured ion. It must be remembered that this composition does not specify individual monosaccharide types such as galactose, mannose etc. that have the same mass. This information must be obtained by other methods such as GC/MS following hydrolysis or exoglycosidase digestions. Also, attempts to completely identify a structure by simply matching the composition to structures in a database is not rigerous enough because of a potentially large number of glycans that could have the same composition. More information (e.g. fragmentation, exoglycosidase digestion, methylation analysis) must be obtained. Experimental details for performing GC/MS analyses can be found in reference (40) and suitable exoglycosidases and incubation protocols are described in the same reference. However, for these virus samples, there probably will not be enough material for GC/MS linkage analysis.

31 A potential problem occurs when preparations of PNGase F contain dithiothreitol (added to denature proteins). This compound can liberate $\mathrm{H}_{2} \mathrm{~S}$ which competes with water when the glycosylamine that is released by the enzyme is hydrolysed to the glycan. Instead of an $\mathrm{OH}$ group at the anomeric position, $\mathrm{H}_{2} \mathrm{~S}$ introduces an $\mathrm{SH}$ group. The mass difference between this group and $\mathrm{OH}$ is 16 which is the mass of oxygen. Thus, the reducing terminal GlcNAc and its attached substituents, such as fucose would appear to contain an extra oxygen. If fucose is present the result can be a mis-diagnosis as hexose. Because the anomeric position and the fucose are lost in formation of the ${ }^{2,4} \mathrm{~A}_{\mathrm{R}}$ ion, the fragmentation spectrum is fully consistent with this incorrect deduction (45). Other groups have also been reported to attach to the reducing terminus in this way, an example being urea (46).
} 
the sialic acid is a2-6-linked (38). Neu5Gc-substituted glycans produce corresponding ions at $\mathrm{m} / \mathrm{z} 306$ and 322 .

11. Glycans containing sulfated GalNAcGlcNAc moieties fragment to give two very prominent ions at $\mathrm{m} / \mathrm{z} 282$ and 485 (Figure 3c).

\section{Notes}

${ }^{1}$ The manually-operated plunge freezer device used in this protocol was custom-built in the Max Planck Institute for Biochemistry, Martinsried, Germany. Semi-automatic alternatives include, for example, those manufactured by FEI (Vitrobot; FEI, Netherlands) and Gatan (Cryo plunge 3; Gatan, USA). If one of the latter devices is used, the blotting protocols may need to be adjusted, and it is of advantage to keep the grids, once loaded with virus sample, in a humid atmosphere. Additionally, other EM grids (molybdenum or copper) may be purchased, such as holey carbon film C-flat grids (Protochips, USA), as long as they have a holey carbon film.

${ }^{2}$ Negative action tweezers can be modified to fit a custom-built plunge-freezer. If a commercial plunge-freezer is used, follow the manufacturer's guidance regarding which tweezers are most appropriate.

${ }^{3}$ DMT-MM can be purchased from Sigma-Aldrich (Product code 74104) or synthesed from $\mathrm{N}$-methylmorpholine and 4-chloro-2,6-dimethoxytriazine by the method described by Kunishima et al. (39).

${ }^{4}$ Waters long thin wall capillaries (part No. M956232AD1 S) are satisfactory or capillaries can be made "in house".

${ }^{5}$ Alternative buffers may be equally suitable as long as they contain $100 \mathrm{mM} \mathrm{NaCl}$ and are held at neutral $\mathrm{pH}$ (e.g. $\mathrm{pH} 7.2$ to $\mathrm{pH}$ 7.5). For example, as an alternative one may use 20 $\mathrm{mM}$ Tris-buffer, $100 \mathrm{mM} \mathrm{NaCl} \mathrm{pH} \mathrm{7.4.} \mathrm{The} \mathrm{use} \mathrm{of} \mathrm{EDTA} \mathrm{in} \mathrm{resuspension} \mathrm{buffer} \mathrm{and} \mathrm{sucrose}$ solution is not essential. If no EDTA is used in the virus resuspension buffer, it needs to be present in the SDS sample buffer ( 2mM EDTA), otherwise there will be aggregation in the wells of the SDS-gel.

${ }^{6}$ All the procedures that involve living cells and virus should be carried out in a standard class 2 biosafety cabinet.

${ }^{7}$ Infectious supernatant can also be harvested before $48 \mathrm{~h}$ incubation, usually once the cells start detaching, which may happen after $\sim 43 \mathrm{~h}$ of incubation already.

${ }^{8}$ Sucrose may be added using $1 \mathrm{ml}$ filter tips or serological pipettes. Care needs to be taken not to overfill the tubes before adding the cushion from the bottom. Ideally, about $30 \mathrm{ml}$ of infectious supernatant can be added first and then $2 \mathrm{ml}$ of sucrose solution. Remaining supernatant may then be added carefully from the top to fill the tube to the maximal recommended volume.

${ }^{9}$ For the overnight incubation step, the ultracentrifuge tubes may be transferred to $50 \mathrm{ml}$ plastic falcon tubes, sealed and stored in a fridge or cold room, to avoid incubation of open containers on ice. Virus pellets should be dissolved for at least two hours.

${ }^{10}$ The amount of viral glycoprotein present in the virus preparation may be estimated by SDS-PAGE analysis using different volumes (e.g. 5-20 $\mu$ of virus preparation), using a reference protein with known concentration. Viral glycoprotein concentrations of Uukuniemi virus pellets are usually in the lower $\mu \mathrm{M}$ range. 
${ }^{11}$ Depending on the exact device available, the glow discharging procedure may be different. In principle, after a vacuum has been pumped, a small amount of air is allowed to flow back into the chamber, to allow plasma formation, which in turn will ionize the carbon film, rendering it more hydrophilic.

${ }^{12}$ Cleaning the sample with a Nafion membrane is only one of several methods that could be adopted. Others include the use of porous graphatized carbon (PGC) (40) or cellulose (41).

${ }^{13}$ Nafion acts as a dialysis membrane allowing ions from salts etc. to diffuse into the water. It also has the ability to adsorb hydrophobic compounds; thus it is not appropriate for cleaning glycans that have been derivatized with e.g. with 2-aminobenzamide (2-AB). ${ }^{14}$ The length of time that the sample should remain on the membrane will depend on the amount of contaminants and should be determined by trial and error. Heavily contaminated samples benefit from leaving for several hours e.g. overnight. If the sample contains glycerol (found in some PNGase F preparations, water will diffuse into the sample, causing swelling and the possibility of samples merging. Such PNGase F preparations should be avoided. ${ }^{15}$ DMSO can be dried with ( $4 \AA, 14$ x 30 mesh) molecular sieve.

16 Methyl iodide is toxic; consequently these steps should be performed in a fume hood. ${ }^{17}$ DMSO has a low volatility and drying may take several hours.

${ }^{18}$ DMT-MM solutions in methanol are relatively unstable and must be made up immediately before use. Alternatively, a small crystal of DMT-MM can be adde to the methanolic glycan solution.

${ }^{19}$ Other ammonium salts could be used at this stage to form the corresponding $[\mathrm{M}+\mathrm{X}]^{-}$ ions.

${ }^{20}$ Many other matrices have been reported for analysis of glycans (42) but DHB is the most widely used.

${ }^{21}$ DHB typically dries to give a target containing large crystals of DHB that point from the perifery of the target towards the center. The purpose of the ethanol is to produce a more uniform target with smaller crystals.

${ }^{22}$ Fragment ions from the transfer cell all have the same mobility and are displayed vertically in a drift time (x axis): $\mathrm{m} / \mathrm{z}$ plot and easily separated from contaminating ions. Fragmentation can also be performed in the trap cell (before fragmentation) allowing mobility data to be collected from each fragment.

${ }^{23}$ For complicated samples, there is a balance between the number of spectra that can be recorded before the sample is exhausted and the signal:noise ratio. Selected ions can be targetted, if know, or if not, a good strategy is to target the abundant ions first as these will require less time for spectral acquisition allowing the maximum number of glycans to be fragmented before the sample is exhausted.

${ }^{24}$ The voltage on the collision cell should not be allowed to rise more than about $30 \mathrm{~V}$ above the recommended value in order to prevent the spectrum changing to one in which most diagnostic ions are missing (43).

${ }^{25}$ Ion selection buttons in DriftScope: The square highlights a rectangular region by dragging the mouse. The triangle extracts a triangular section. The circle allows the user to draw around the region of interest and the half-filled square is used to highlight a region by clicking at various points around the region of interest (double click to close the selected region). 
${ }^{26}$ Isomers and conformers can usually be differentiated by plotting corresponding mobilograms of fragment ions. If these have the same profile as that of the molecular ion, assymetry is probably due to conformers. If not, isomers are present.

27 Any ion that falls within the window used by the quadrupole will produce fragments. With mixtures, it is often the case that several ions can be selected and each will produce fragments. See the example of $\mathrm{m} / \mathrm{z} 1007$ discussed above.

${ }^{28}$ With ammonium phosphate added to the ESI solvent, most adducts should be phosphate (addition of 96.969 mass units). However, there is the possibility that sufficient chloride is present to produce additional chloride adducts (addition of 34.969 units $\left({ }^{35} \mathrm{Cl}\right.$ isotope)). Thus, it is important to determine which adduct is present. Chloride adducts can often be identified by the presence of the ${ }^{35} \mathrm{Cl}$ and ${ }^{37} \mathrm{Cl}$ chloride isotopes. Negative ion MALDI spectra with ammoniun nitrate added to the matrix will, of course, produce nitrate adducts (addition of 61.989 units). Positive ion MALDI adducts are invariably sodium (22.989 units).

${ }^{29}$ The $B_{R-1}$ ion is 60 mass units less in mass than the ${ }^{2,4} \mathrm{AR}$ ion and the ${ }^{2,4} \mathrm{~A}_{\mathrm{R}-1}$ ion is 203 mass units lower if the penultimate GlcNAc contains no fucose, or 349 units lower if it contains a single fucose.

${ }^{30}$ The isobaric monosaccharide content is the number of hexose, HexNAc residues etc. The mass of the resulting ion is given by adding the residue masses of the monosaccharides (listed in Table 2), the mass of the adduct and the mass of one molecule of water (18.01). A spread sheet, a home-constructed software program or the use of an internet-available program such as GlycoMod (44) or that in GlycoWorkbench (http://glycomics.ccrc.uga.edu/ eurocarb/gwb/home.action) can be used to obtain the composition from the measured mass. Unfortunately, the GlycoWorkbench algorithm does not work in negative ion mode but compositions can be obtained by using a mass corresponding to the experimentally measused mass, by subtraction of the mass of the adduct minus 1 (i.e. the mass of the [M $+1]^{+}$ion) from that of the measured ion. It must be remembered that this composition does not specify individual monosaccharide types such as galactose, mannose etc. that have the same mass. This information must be obtained by other methods such as GC/MS following hydrolysis or exoglycosidase digestions. Also, attempts to completely identify a structure by simply matching the composition to structures in a database is not rigerous enough because of a potentially large number of glycans that could have the same composition. More information (e.g. fragmentation, exoglycosidase digestion, methylation analysis) must be obtained. Experimental details for performing GC/MS analyses can be found in reference (40) and suitable exoglycosidases and incubation protocols are described in the same reference. However, for these virus samples, there probably will not be enough material for GC/MS linkage analysis.

${ }^{31}$ A potential problem occurs when preparations of PNGase F contain dithiothreitol (added to denature proteins). This compound can liberate $\mathrm{H}_{2} \mathrm{~S}$ which competes with water when the glycosylamine that is released by the enzyme is hydrolysed to the glycan. Instead of an $\mathrm{OH}$ group at the anomeric position, $\mathrm{H}_{2} \mathrm{~S}$ introduces an $\mathrm{SH}$ group. The mass difference between this group and $\mathrm{OH}$ is 16 which is the mass of oxygen. Thus, the reducing terminal GlcNAc and its attached substituents, such as fucose would appear to contain an extra oxygen. If fucose is present the result can be a mis-diagnosis as hexose. Because the anomeric position and the fucose are lost in formation of the ${ }^{2,4} \mathrm{~A}_{\mathrm{R}}$ ion, the fragmentation spectrum is fully 
consistent with this incorrect deduction (45). Other groups have also been reported to attach to the reducing terminus in this way, an example being urea (46).

\section{Acknowledgments}

M.C. is supported by the Center for HIV/AIDS Vaccine Immunology and Immunogen Discovery Grant (UM1 AI100663) and the International AIDS Vaccine Initiative through the Neutralizing Antibody Consortium and Bill and Melinda Gates Center for Vaccine Discovery. M.C. is a Fellow of Oriel College, Oxford. We also thank the Wellcome Trust (grant number 090532/Z/09/Z; 089026/Z/09/Z to T.A.B.), the Academy of Finland (grant numbers 130750 and 218080 to J.T.H.), and the MRC (MR/L009528/1 to T.A.B. and MR/K024426/1 to K.J.D) for funding.

\section{Abbreviations}

\begin{tabular}{|c|c|}
\hline 2-AA & 2-aminobenzoic acid (anthranillic acid) \\
\hline 2-AB & 2-aminobenzamide \\
\hline BHK & baby hamster kidney \\
\hline CCD & charge-coupled device \\
\hline CID & collision-induced dissociation \\
\hline DC-SIGN & $\begin{array}{l}\text { dendritic cell-specific intercellular adhesion molecule-3-grabbing non- } \\
\text { integrin }\end{array}$ \\
\hline DHB & 2,5-dihydroxybenzoic acid \\
\hline DMSO & dimethylsulfoxide \\
\hline DMT-MM & 4-(4,6-dimethoxy-1,3,5-triazin-2-yl)-4-methylmorpholinium chloride \\
\hline EDTA & ethylenediaminetetraacetate \\
\hline ESI & electrospray ionization \\
\hline Fuc & fucose \\
\hline Gal & galactose \\
\hline GC/MS & gas chromatography/mass spectrometry \\
\hline GlcNAc & $N$-acetylglucosamine \\
\hline GMEM & Glasgow's Minimum Essential Medium \\
\hline H20N100E2 & 20 mM HEPES, 100 mM NaCl, 2 mM EDTA \\
\hline HEPES & 4-(2-Hydroxyethyl)piperazine-1-ethanesulfonic acid \\
\hline HPLC & high-performance liquid chromatography \\
\hline MALDI & matrix-assisted laser desorption/ionization \\
\hline Man & mannose \\
\hline MoI & multiplicity of infection \\
\hline MS & mass spectrometry \\
\hline Neu5Ac & $N$-acetylneuraminic acid (sialic acid) \\
\hline
\end{tabular}




$\begin{array}{ll}\text { Neu5Gc } & N \text {-glycoylneuraminic acid } \\ \text { PCR } & \text { polymerase chain reaction } \\ \text { PGC } & \text { porous graphatized carbon } \\ \text { PNGase F } & \text { protein- } N \text {-glycosidase F } \\ \text { PBS } & \text { phosphate-buffered saline } \\ \text { Q } & \text { quadrupole } \\ \text { SDS } & \text { sodium dodecylsulfate } \\ \text { THAP } & 2,4,6 \text {-trihydroxyacetophenone } \\ \text { TOF } & \text { time-of-flight }\end{array}$

Tris-base

2-Amino-2-(hydroxymethyl)-1,3-propanediol

UUKV

Uukuniemi virus

\section{References}

1. Bowden TA, Jones EY, Stuart DI. Cells under siege: viral glycoprotein interactions at the cell surface. Journal of structural biology. 2011; 175:120-126. [PubMed: 21440638]

2. Rossmann MG. Structure of viruses: a short history. Quartly Reviews of Biophysics. 2013; 46:133180.

3. Chang VT, Crispin M, Aricescu AR, Harvey DJ, Nettleship JE, Fennelly JA, Yu C, Boles KS, Evans EJ, Stuart DI, Dwek RA, Jones EY, Owens RJ, Davis SJ. Glycoprotein structural genomics: solving the glycosylation problem. Structure. 2007; 15:267-273. [PubMed: 17355862]

4. Lozach PY, Kuhbacher A, Meier R, Mancini R, Bitto D, Bouloy M, Helenius A. DC-SIGN as a receptor for phleboviruses. Cell host \& microbe. 2011; 10:75-88. [PubMed: 21767814]

5. Alexandre KB, Gray ES, Lambson BE, Moore PL, Choge IA, Mlisana K, Karim SS, McMahon J, O'Keefe B, Chikwamba R, Morris L. Mannose-rich glycosylation patterns on HIV-1 subtype C gp120 and sensitivity to the lectins, Griffithsin, Cyanovirin-N and Scytovirin. Virology. 2010; 402:187-196. [PubMed: 20392471]

6. Bonomelli C, Doores KJ, Dunlop DC, Thaney V, Dwek RA, Burton DR, Crispin M, Scanlan CN. The glycan shield of HIV is predominantly oligomannose independently of production system or viral clade. PLoS One. 2011; 6:e23521. [PubMed: 21858152]

7. Doores KJ, Bonomelli C, Harvey DJ, Vasiljevic S, Dwek RA, Burton DR, Crispin M, Scanlan CN. Envelope glycans of immunodeficiency virions are almost entirely oligomannose antigens. Proc Natl Acad Sci U S A. 2010; 107:13800-13805. [PubMed: 20643940]

8. Walker LM, Huber M, Doores KJ, Falkowska E, Pejchal R, Julien JP, Wang SK, Ramos A, ChanHui PY, Moyle M, Mitcham JL, Hammond PW, Olsen OA, Phung P, Fling S, Wong CH, Phogat S, Wrin T, Simek MD, Koff WC, Wilson IA, Burton DR, Poignard P. Broad neutralization coverage of HIV by multiple highly potent antibodies. Nature. 2011; 477:466-470. [PubMed: 21849977]

9. Scanlan CN, Pantophlet R, Wormald MR, Ollmann Saphire E, Stanfield R, Wilson IA, Katinger H, Dwek RA, Rudd PM, Burton DR. The broadly neutralizing anti-human immunodeficiency virus type 1 antibody $2 \mathrm{G} 12$ recognizes a cluster of alpha1-->2 mannose residues on the outer face of gp120. J Virol. 2002; 76:7306-7321. [PubMed: 12072529]

10. Kornfeld R, Kornfeld S. Assembly of asparagine-linked oligosaccharides. Annual review of biochemistry. 1985; 54:631-664.

11. Walker LM, Phogat SK, Chan-Hui PY, Wagner D, Phung P, Goss JL, Wrin T, Simek MD, Fling S, Mitcham JL, Lehrman JK, Priddy FH, Olsen OA, Frey SM, Hammond PW, Kaminsky S, Zamb T, Moyle M, Koff WC, Poignard P, Burton DR. Broad and potent neutralizing antibodies from an 
African donor reveal a new HIV-1 vaccine target. Science. 2009; 326:285-289. [PubMed: 19729618]

12. Bonsignori M, Hwang KK, Chen X, Tsao CY, Morris L, Gray E, Marshall DJ, Crump JA, Kapiga SH, Sam NE, Sinangil F, Pancera M, Yongping Y, Zhang B, Zhu J, Kwong PD, O'Dell S, Mascola JR, Wu L, Nabel GJ, Phogat S, Seaman MS, Whitesides JF, Moody MA, Kelsoe G, Yang X, Sodroski J, Shaw GM, Montefiori DC, Kepler TB, Tomaras GD, Alam SM, Liao HX, Haynes BF. Analysis of a clonal lineage of HIV-1 envelope V2/V3 conformational epitope-specific broadly neutralizing antibodies and their inferred unmutated common ancestors. J Virol. 2011; 85:999810009. [PubMed: 21795340]

13. Falkowska E, Le KM, Ramos A, Doores KJ, Lee JH, Blattner C, Ramirez A, Derking R, van Gils MJ, Liang CH, McBride R, von Bredow B, Shivatare SS, Wu CY, Chan-Hui PY, Liu Y, Feizi T, Zwick MB, Koff WC, Seaman MS, Swiderek K, Moore JP, Evans D, Paulson JC, Wong CH, Ward AB, Wilson IA, Sanders RW, Poignard P, Burton DR. Broadly neutralizing HIV antibodies define a glycan-dependent epitope on the prefusion conformation of gp41 on cleaved envelope trimers. Immunity. 2014; 40:657-668. [PubMed: 24768347]

14. Crispin M, Bowden TA. Antibodies expose multiple weaknesses in the glycan shield of HIV. Nature structural \& molecular biology. 2013; 20:771-772.

15. Dalziel M, Crispin M, Scanlan CN, Zitzmann N, Dwek RA. Emerging principles for the therapeutic exploitation of glycosylation. Science. 2014; 343:1235681. [PubMed: 24385630]

16. Burton DR, Ahmed R, Barouch DH, Butera ST, Crotty S, Godzik A, Kaufmann DE, McElrath MJ, Nussenzweig MC, Pulendran B, Scanlan CN, Schief WR, Silvestri G, Streeck H, Walker BD, Walker LM, Ward AB, Wilson IA, Wyatt R. A Blueprint for HIV Vaccine Discovery. Cell host \& microbe. 2012; 12:396-407. [PubMed: 23084910]

17. Bowden TA, Crispin M, Harvey DJ, Jones EY, Stuart DI. Dimeric architecture of the Hendra virus attachment glycoprotein: Evidence for a conserved mode of assembly. J Virol. 2010; 84:62086217. [PubMed: 20375167]

18. Crispin M, Harvey DJ, Bitto D, Halldorsson S, Bonomelli C, Edgeworth M, Scrivens JH, Huiskonen JT, Bowden TA. Uukuniemi phlebovirus assembly and secretion leave a functional imprint on the virion glycome. Journal of virology. 2014; 88:10244-10251. [PubMed: 24942574]

19. Powell AK, Harvey DJ. Stabilisation of sialic acids in $N$-linked oligosaccharides and gangliosides for analysis by positive ion matrix-assisted laser desorption-ionization mass spectrometry. Rapid Communications in Mass Spectrometry. 1996; 10:1027-1032. [PubMed: 8755235]

20. Wheeler SF, Domann P, Harvey DJ. Derivatization of sialic acids for stabilization in matrixassisted laser desorption/ionization mass spectrometry and concomitant differentiation of a(2-3) and a(2-6) isomers. Rapid Communications in Mass Spectrometry. 2009; 23:303-312. [PubMed: 19089860]

21. Liu X, Qiu H, Lee RK, Chen W, Li J. Methylamidation for sialoglycomics by MALDI-MS: A facile derivatization strategy for both a2,3- and a2,6-linked sialic acids. Analytical Chemistry. 2010; 82:8300-8306. [PubMed: 20831242]

22. Harvey DJ. Fragmentation of negative ions from carbohydrates: Part 2, Fragmentation of highmannose $N$-linked glycans. Journal of the American Society for Mass Spectrometry. 2005; 16:631-646. [PubMed: 15862765]

23. Harvey DJ. Fragmentation of negative ions from carbohydrates: Part 1; Use of nitrate and other anionic adducts for the production of negative ion electrospray spectra from $N$-linked carbohydrates. Journal of the American Society for Mass Spectrometry. 2005; 16:622-630. [PubMed: 15862764]

24. Harvey DJ. Fragmentation of negative ions from carbohydrates: Part 3, Fragmentation of hybrid and complex $N$-linked glycans. Journal of the American Society for Mass Spectrometry. 2005; 16:647-659. [PubMed: 15862766]

25. Harvey DJ, Royle L, Radcliffe CM, Rudd PM, Dwek RA. Structural and quantitative analysis of $N$-linked glycans by MALDI and negative ion nanospray mass spectrometry. Analytical biochemistry. 2008; 376:44-60. [PubMed: 18294950]

26. Domon B, Costello CE. A systematic nomenclature for carbohydrate fragmentations in FABMS/MS spectra of glycoconjugates. Glycoconj J. 1988; 5:397-409. 
27. Harvey DJ, Scarff CA, Crispin M, Scanlan CN, Bonomelli C, Scrivens JH. MALDI-MS/MS with traveling wave ion mobility for the structural analysis of $N$-linked glycans. J Am Soc Mass Spectrom. 2012; 23:1955-1966. [PubMed: 22993039]

28. Harvey DJ, Scarff CA, Edgeworth M, Crispin M, Scanlan CN, Sobott F, Allman S, Baruah K, Pritchard L, Scrivens JH. Travelling wave ion mobility and negative ion fragmentation for the structural determination of N-linked glycans. Electrophoresis. 2013; 34:2368-2378. [PubMed: 23712623]

29. Pettersson R, Kääriäinen L. The ribonucleic acids of Uukuniemi virus, a noncubical tick-borne arbovirus. Virology Journal. 1973; 56:608-619.

30. Lozach PY, Mancini R, Bitto D, Meier R, Oestereich L, Overby AK, Pettersson RF, Helenius A. Entry of bunyaviruses into mammalian cells. Cell Host and Microbe. 2010; 7:488-499. [PubMed: 20542252]

31. Pettersson R, Kääriäinen L, von Bonsdorff CH, Oker-Blom N. Structural components of Uukuniemi virus, a noncubical tick-borne arbovirus. Virology. 1971; 46:721-729. [PubMed: 4109526]

32. Grassucci RA, Taylor D, Frank J. Visualization of macromolecular complexes using cryo-electron microscopy with FEI Tecnai transmission electron microscopes. Nature Protocols. 2008; 3:330339. [PubMed: 18274535]

33. Cyrklaff M, Roos N, Gross H, Dubochet J. Particle surface interacion in thin vitrified films for cryo-electron microscopy. Journal of Microscopy. 1994; 175:135-142.

34. Crispin M, Harvey DJ, Bitto D, Bonomelli C, Edgeworth M, Scrivens JH, Huiskonen JT, Bowden TA. Structural plasticity of the Semliki Forest virus glycome upon interspecies transmission. Journal of Proteome Research. 2014; 13:1702-1712. [PubMed: 24467287]

35. Börnsen KO, Mohr MD, Widmer HM. Ion exchange and purification of carbohydrates on a Nafion ${ }^{(R)}$ membrane as a new sample pretreatment for matrix-assisted laser desorption-ionization mass spectrometry. Rapid Communications in Mass Spectrometry. 1995; 9:1031-1034.

36. Domann P, Spencer DIR, Harvey DJ. Production and fragmentation of negative ions from neutral $N$-linked carbohydrates ionized by matrix-assisted laser desorption/ionization. Rapid Communications in Mass Spectrometry. 2012; 26:469-479. [PubMed: 22279023]

37. Harvey DJ, Crispin M, Scanlan C, Singer BB, Lucka L, Chang VT, Radcliffe CM, Thobhani S, Yuen CT, Rudd PM. Differentiation between isomeric triantennary $N$-linked glycans by negative ion tandem mass spectrometry and confirmation of glycans containing galactose attached to the bisecting ( $\beta 1-4-G l c N A c)$ residue in $N$-glycans from IgG. Rapid Communications in Mass Spectrometry. 2008; 22:1047-1052. [PubMed: 18327885]

38. Wheeler SF, Harvey DJ. Negative ion mass spectrometry of sialylated carbohydrates: Discrimination of $N$-acetylneuraminic acid linkages by matrix-assisted laser desorption/ionizationtime-of-flight and electrospray-time-of-flight mass spectrometry. Analytical Chemistry. 2000; 72:5027-5039. [PubMed: 11055725]

39. Kunishima M, Kawachi C, Morita J, Terao K, Iwasaki F, Tani S. 4-(4,6-Dimethoxy-1,3,5-triazin-2yl)-4-methyl-morpholinium chloride: An efficient condensing agent leading to the formation of amides and esters. Tetrahedron. 1999; 55:13159-13170.

40. Morelle W, Michalski JC. Analysis of protein glycosylation by mass spectrometry. Nature Protocols. 2007; 2:1585-1602. [PubMed: 17585300]

41. Selman MHJ, Hemayatkar M, Deelder AM, Wuhrer M. Cotton HILIC SPE microtips for microscale purification and enrichment of glycans and glycopeptides. Analytical Chemistry. 2011; 83:2492-2499. [PubMed: 21366235]

42. Hossain, M.; Limbach, PA. A comparison of MALDI matrices. In: Cole, RB., editor. Electrospray and MALDI Mass Spectrometry: Fundamentals, Instrumentation, Practicalities, and Biological Applications, 2nd Edition. John Wiley and Sons Inc; Hoboken, NJ, USA: 2010. p. 215-244.

43. Harvey DJ, Edgeworth M, Krishna BA, Bonomelli C, Allman S, Crispin M, Scrivens JH. Fragmentation of negative ions from $N$-linked carbohydrates: Part 6: Glycans containing one Nacetylglucosamine in the core. Rapid Communications in Mass Spectrometry. 2014; 28:20082018. [PubMed: 25132301] 
44. Cooper CA, Gasteiger E, Packer NH. GlycoMod - A software tool for determining glycosylation compositions from mass spectrometric data. Proteomics. 2001; 1:340-349. [PubMed: 11680880]

45. Harvey DJ, Rudd PM. Identification of by-products formed during the release of $\mathrm{N}$-glycans with protein $N$-glycosidase F in the presence of dithiothreitol. Journal of Mass Spectrometry. 2010; 45:815-819. [PubMed: 20623555]

46. Omtvedt LA, Royle L, Husby G, Sletten K, Radcliffe C, Dwek RA, Rudd PM, Harvey DJ. Artefacts formed by addition of urea to $N$-linked glycans released with peptide- $N$-glycosidase F for analysis by mass spectrometry. Rapid Communications in Mass Spectrometry. 2004; 18:23572359. [PubMed: 15384159]

47. Harvey DJ, Merry AH, Royle L, Campbell MP, Dwek RA, Rudd PM. Proposal for a standard system for drawing structural diagrams of $N$ - and $O$-linked carbohydrates and related compounds. Proteomics. 2009; 9:3796-3801. [PubMed: 19670245] 


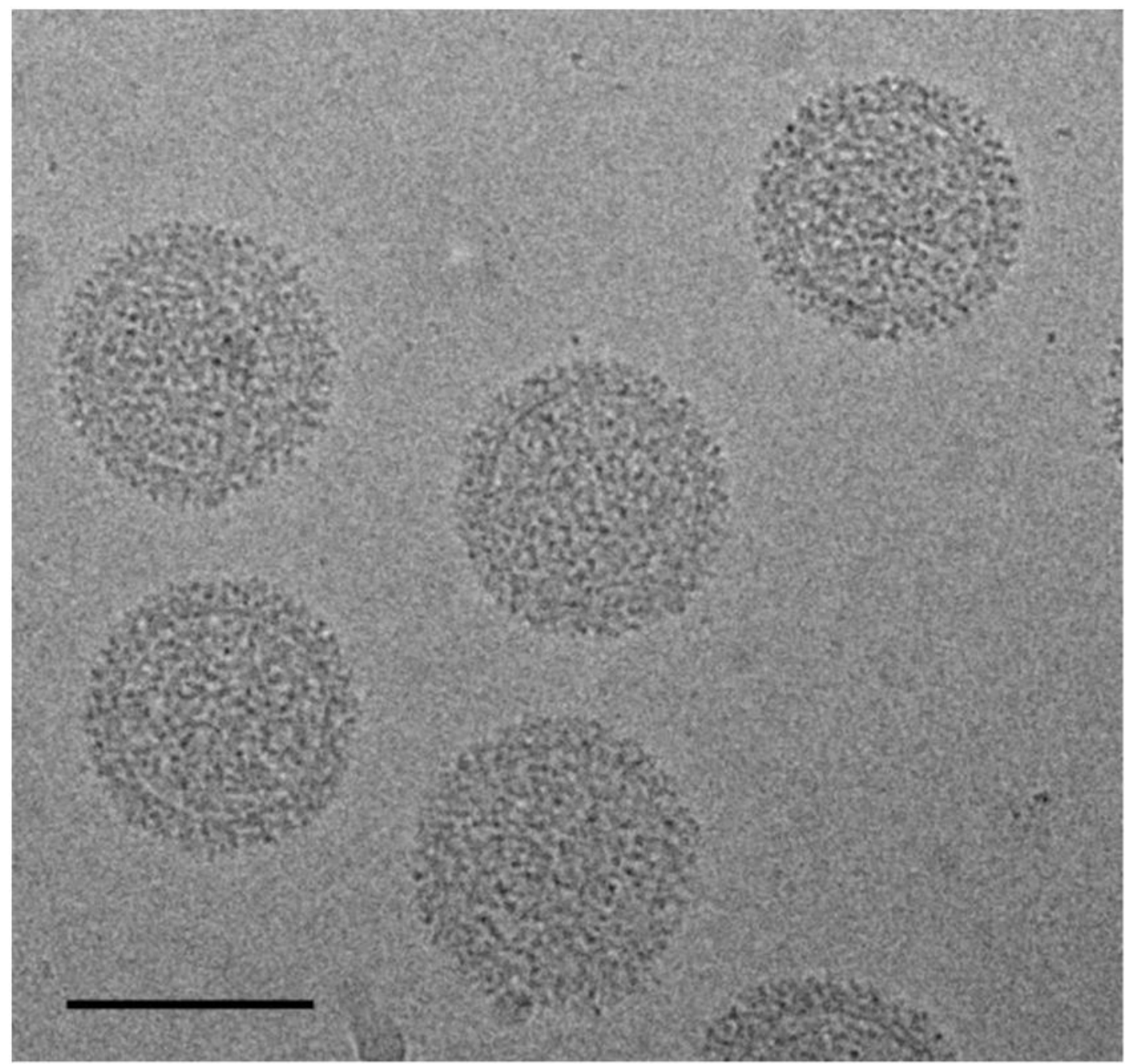

Figure 1.

Two-dimensional projection image of concentrated UUKV supernatant, plunge-frozen at liquid nitrogen temperature. Image was acquired on a FEI Tecnai Polara, at $-5 \mu \mathrm{m}$ defocus, $300 \mathrm{kV}$, and a nominal magnification of 59000x (75000x calibrated magnification), leading to a calibrated pixel size of $2 \AA /$ pixel. The images were recorded with a charge-coupled device (CCD) camera (Ultrascan 4000, Gatan, USA), in low dose mode, using 20 electrons $/ \AA^{2}$. Scale bar corresponds to $100 \mathrm{~nm}$. 


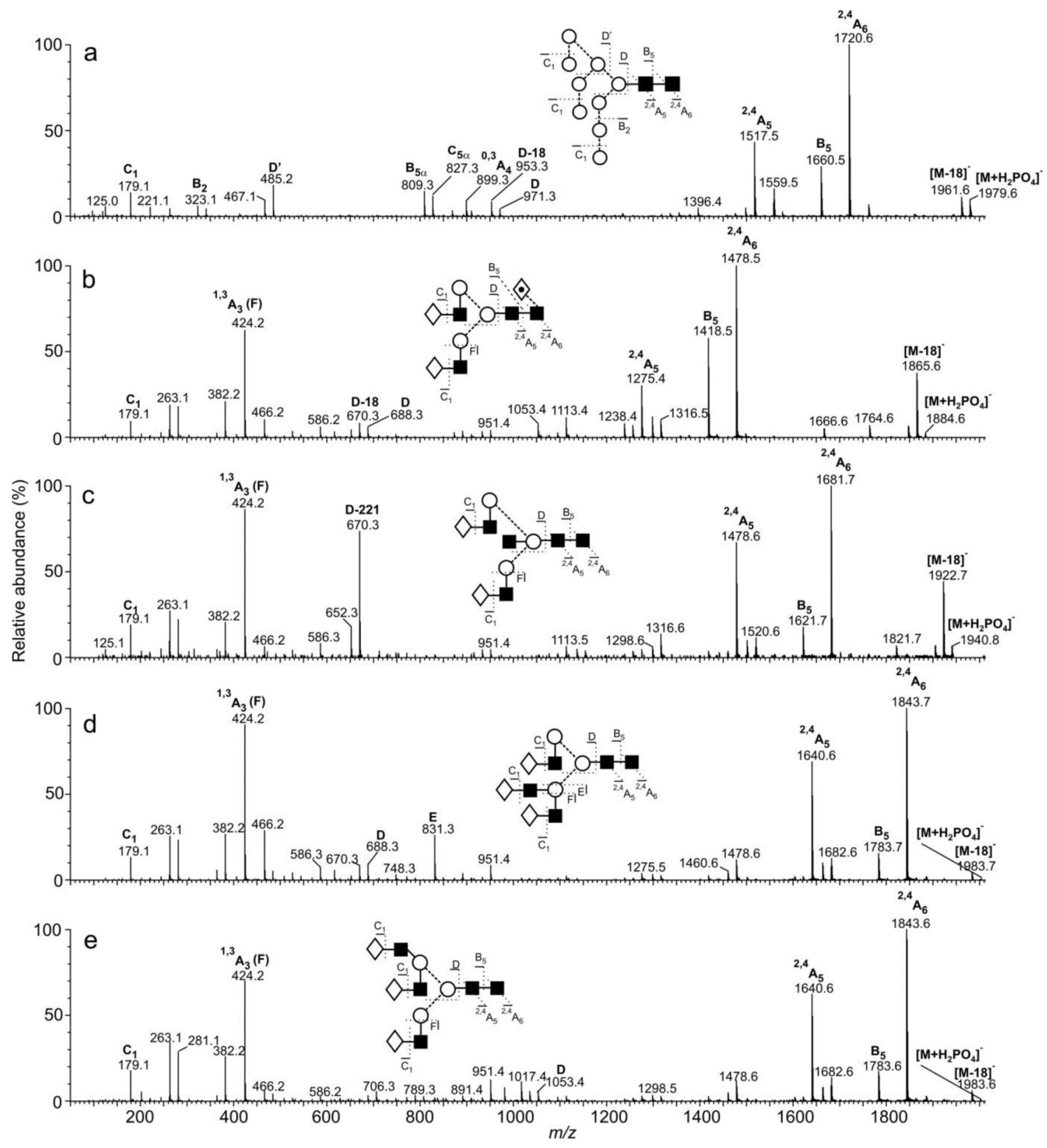

Figure 2.

Negative ion CID spectra of typical $N$-glycans (phosphate adducts). (a) High-mannose glycan Man 9 GlcNAc $_{2} \cdot{ }^{2,4} \mathrm{~A}_{6}, \mathrm{~B}_{5}$ and ${ }^{2,4} \mathrm{~A}_{5}$ ions defining the trimannosylchitobiose core are at $\mathrm{m} / \mathrm{z}$ 1720. 1660 and 1517 respectively. The $\mathrm{C}_{1}$ ion at $\mathrm{m} / \mathrm{z} 179$ shows hexose (mannose) at the non-reducing termini of the antennae. The D, D-18, ${ }^{0,4} \mathrm{~A}_{4},{ }^{0,3} \mathrm{~A}_{4}$ and $\mathrm{B}_{3 a}$ ions defining the composition of the 6 -antenna are at $m / z 971,953,899,869$ and 809 , respectively and the D' ion at $m / z 485$ shows the composition of the 6-branch of the 6-antenna. (b) Fucosylated biantennary glycan $\mathrm{Gal}_{2} \mathrm{Man}_{3} \mathrm{GlcNAc}_{4} \mathrm{Fuc}_{1}$. The presence of the 6-linked core fucose is revealed by the 405 mass unit difference between the molecular ion and the ${ }^{2,4} \mathrm{~A}_{6}$ ion at $\mathrm{m} / \mathrm{Z}$ 1478.5. The $\mathrm{C}_{1}$ ion at $\mathrm{m} / z 179$ shows hexose (galactose) at the termini of the antennae and 
the ${ }^{1,3} \mathrm{~A}_{3}$ cross-ring ion at $\mathrm{m} / \mathrm{z} 424$ (labelled F) confirms the Gal-GlcNAc composition of the antennae. The D and D-18 ions at $m / z 688$ and 670 respectively show the composition of the 6-antenna. (c) Bisected biantennary glycan $\mathrm{Gal}_{2} \mathrm{Man}_{3} \mathrm{GlcNAc}_{5}$. Most diagnostic ions are as for the glycans in spectra $\mathbf{a}$ and $\mathbf{b}$. The presence of the bisecting GlcNAc is revealed by the very prominent ion at $m / z 670$ corresponding to D-221 mass units. (d) Triantennary glycan $\mathrm{Gal}_{3} \mathrm{Man}_{3} \mathrm{GlcNAc}_{5}$. Branching of the 3-antenna gives rise to the ion at $\mathrm{m} / \mathrm{z} 831$ (labelled E). The unbranched 6-antenna produces D and D-18 ions at $m / z 688$ and 760 as in the spectrum of the biantennary glycan (spectrum b). (e) Triantennary glycan $\mathrm{Gal}_{3} \mathrm{Man}_{3} \mathrm{GlcNAc}_{5}$. The branching pattern is shown by the absence of ion $\mathrm{E}$ and the shift in the D and D-18 ions to $\mathrm{m} / \mathrm{z} 1053$ and 1035 respectively. These ions are accompanied by a third ion at $\mathrm{m} / \mathrm{z} 1017$ (D-36). Fragments are named according to the scheme proposed by Domon and Costello (see Figure 4) (26). Key to symbols used for the structural diagrams: $\diamond=$ Gal, $\boldsymbol{\square}=$ GlcNAc, $\bigcirc=$ Man, $\diamond=$ Fuc, $\star=$ sialic acid. The angle of the lines linking the symbols denotes the linkage poisition ( $\mid=2$-link, / = 3-link, - = 4-link, $\backslash=6$-link) with full lines for $\beta$-bonds and broken lines for a-bonds. For further details, see (47). 

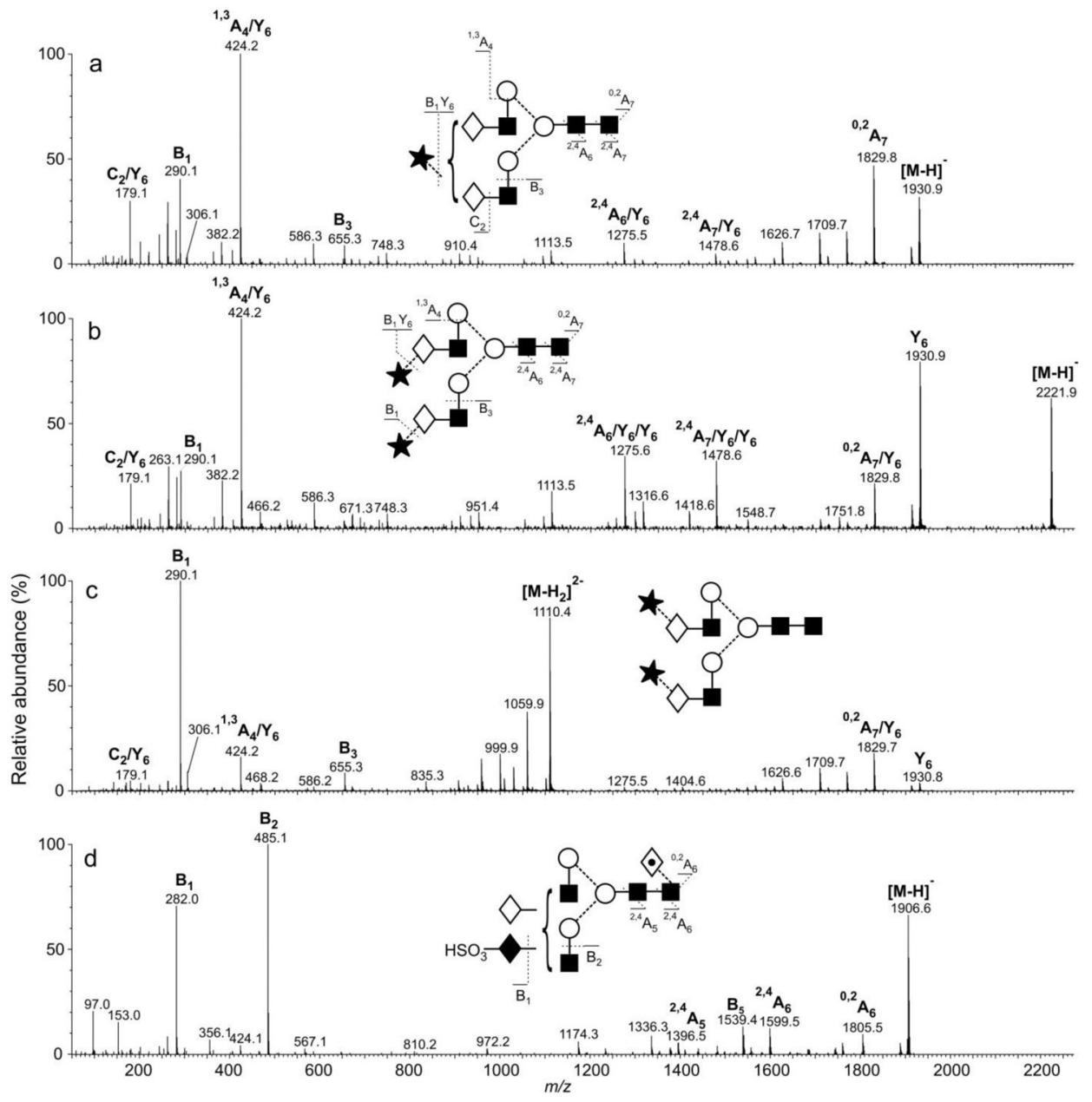

Figure 3.

Negative ion CID spectra of sialylated glycans. (a) Monosialylated biantennary glycan $\mathrm{Gal}_{2} \mathrm{Man}_{3} \mathrm{GlcNAc}_{4} \mathrm{Neu}_{5} \mathrm{Ac}_{1}$. The presence of the ${ }^{0.2} \mathrm{~A}_{7}(\mathrm{~m} / z$ 1829) ion is typical of these compounds. The sialic acid residue is seen as the $B_{1}$ ion at $m / z 290$ and this ion is accompanied by a relatively low abundance ion at $\mathrm{m} / \mathrm{z} 306$ showing the $\mathrm{a} 2 \rightarrow 6$ linkage. ${ }^{2,4} \mathrm{~A}_{6},{ }^{2,4} \mathrm{~A}_{7}$ and ${ }^{1,3} \mathrm{~A}_{4}$ ions are present $(\mathrm{m} / \mathrm{z} 1275,1478$ and 424$)$ but are formed with additional loss of sialic acid. (b) Di-sialylated biantennary glycan $\mathrm{Gal}_{2} \mathrm{Man}_{3} \mathrm{GlcNAc}_{4} \mathrm{Neu}_{5} \mathrm{Ac}_{2}$ (singly charged ion). Fragments in the spectrum of this compound are similar to those in the spectrum of the monosialylated glycan except that most of the main diagnostic fragments have lost both sialic acid moieties. The ${ }^{2,4} \mathrm{~A}_{6}$ and ${ }^{2,4} \mathrm{~A}_{7}$ ions (with losses of sialic acid ( $\mathrm{m} / \mathrm{z} 1275$ and 1478 respectively) are generally more abundant in the spectra of glycans containing a $2 \rightarrow 3$-linked sialic acid (as shown here) than in the spectra of glycans bearing a $2 \rightarrow 6$-linked sialic acids. (c) Di-sialylated biantennary glycan $\mathrm{Gal}_{2} \mathrm{Man}_{3} \mathrm{GlcNAc}_{4} \mathrm{Neu} 5 \mathrm{Ac}_{2}$ (doubly charged ion). Some singly charged fragments (ions at higher mass that the $\left[\mathrm{M}-\mathrm{H}_{2}\right]^{2-}$ ion at $\mathrm{m} / \mathrm{z} 1110$ ) are formed by loss of one of the sialic acid groups. Most of the diagnostic ions seen in the spectra of the neutral compounds are suppressed, a trend that becomes more apparent as the number of sialic acid groups 
increases. Symbols for the structural diagrams are as defined in the footnote to Figure 2 plus: $\bullet=$ Neu5Ac, $\square=$ GalNAc. 


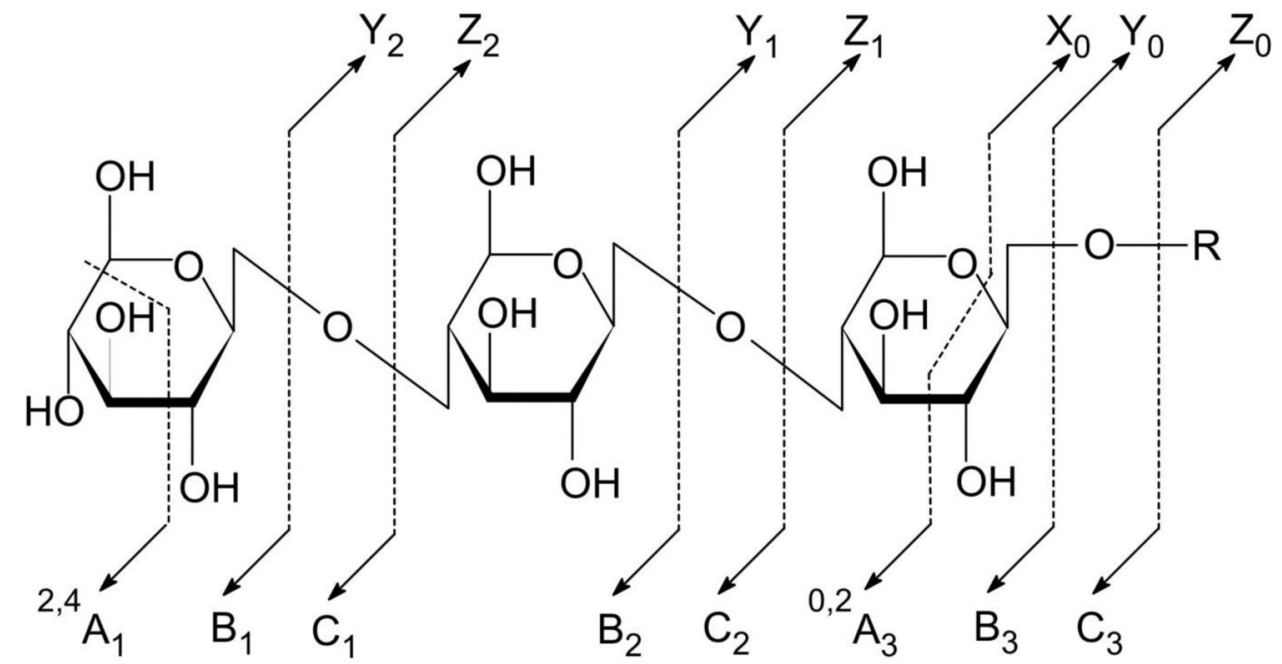

Figure 4.

Domon and Costello system for naming the fragment ions. $\mathrm{R}=\mathrm{H}$ or attached lipid (as in gangliosides). 

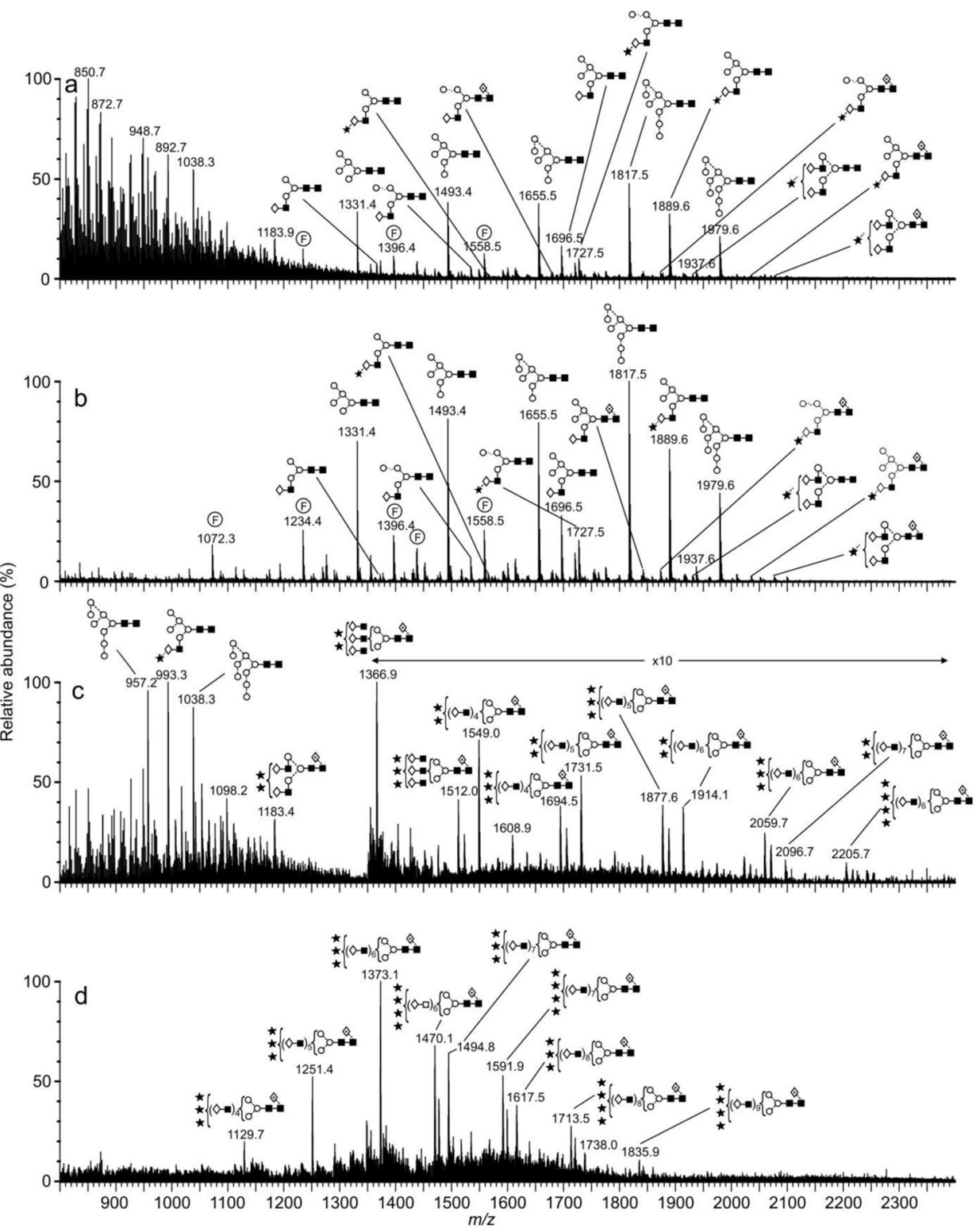

Figure 5.

(a) Electrospray spectrum of $\mathrm{N}$-glycans released from the Gc virion glycoprotein from Uukuniemi virus. (b) Extracted singly charged ions from region 1 of Figure 6. (c) Extracted doubly charged ions from region 2 of Figure 6. (d) Extracted triply charged ions from region 3 of Figure 6. 


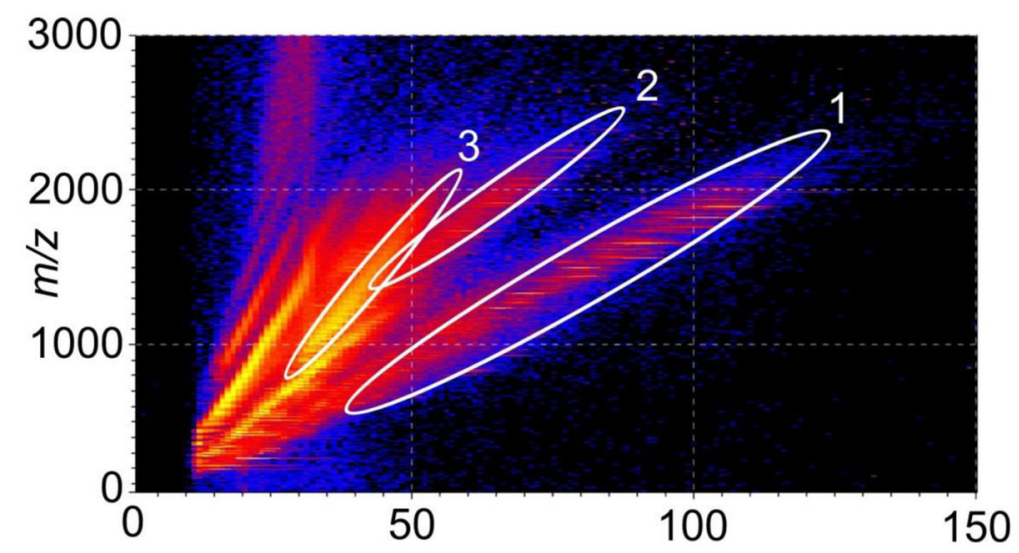

Figure 6.

Driftscope display (drift time: $\mathrm{m} / z$ ) of $\mathrm{N}$-glycans released from the Gc virion glycoprotein from Uukuniemi virus (UUKV). Circled areas are: $1=$ singly charged ions, $2=$ doubly charged ions, 3 = triply charged ions. Extracted spectra are shown in Figure 5 (b-d). Further details are in reference (18). 


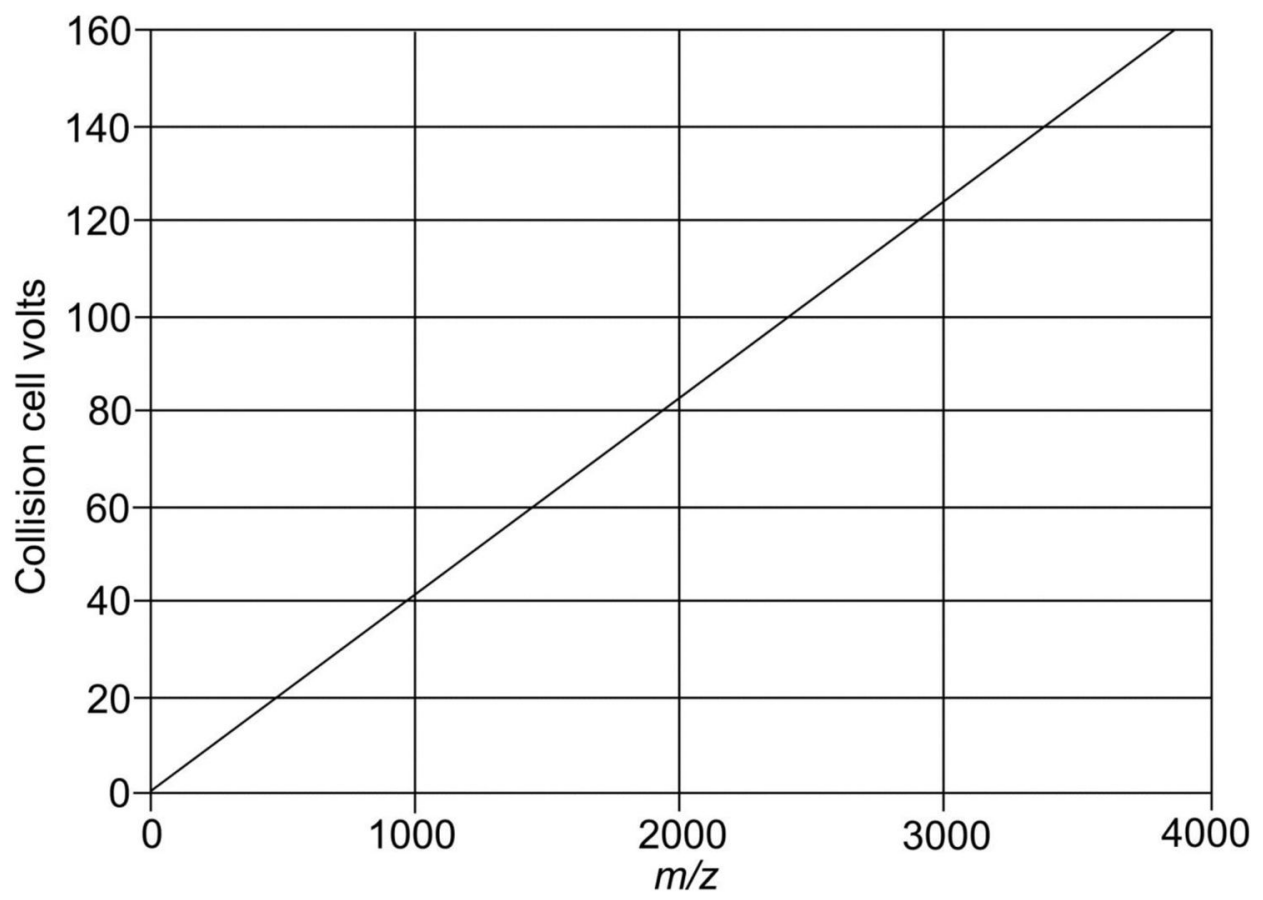

Figure 7.

Guide for setting the collision cell voltage with respect to mass for acquisition of CID spectra. The optimum voltage will depend on the glycan structure and could vary by about $\pm 10 \mathrm{~V}$ 
Table 1

\begin{tabular}{|c|c|c|c|c|}
\hline \multirow{8}{*}{ 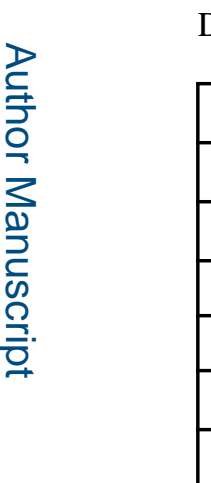 } & \multicolumn{4}{|c|}{ Determination of adduct } \\
\hline & {$[\mathrm{M}+\mathrm{X}]^{-} \mathbf{- ~}^{2,4} \mathrm{~A}_{\mathrm{R}}$} & Fuc on $R$ & Fuc on R-1 & Adduct (X) \\
\hline & 405 & 0 & 1 & {$\left[\mathrm{H}_{2} \mathrm{PO}_{4}\right]^{-}$} \\
\hline & 551 & 1 & 1 & {$\left[\mathrm{H}_{2} \mathrm{PO}_{4}\right]^{-}$} \\
\hline & 343 & 0 & 1 & {$[\mathrm{Cl}]^{-}$} \\
\hline & 459 & 1 & 1 & {$[\mathrm{Cl}]^{-}$} \\
\hline & 364 & 0 & 1 & {$\left[\mathrm{H}_{2} \mathrm{PO}_{4}\right]^{-}$} \\
\hline & 510 & 1 & 1 & {$\left[\mathrm{H}_{2} \mathrm{PO}_{4}\right]^{-}$} \\
\hline
\end{tabular}

${ }^{1}$ Reducing terminal GlcNAc, R-1 = penultimate GlcNAc residue. 


\section{Table 2}

\section{Residue masses of common monosaccharides}

\begin{tabular}{|l|l|l|}
\hline Monosaccharide & Residue formula & Residue mass \\
\hline Pentose & $\mathrm{C}_{5} \mathrm{H}_{8} \mathrm{O}_{4}$ & 132.042 \\
& & 132.116 \\
\hline Deoxy-hexose & $\mathrm{C}_{6} \mathrm{H}_{10} \mathrm{O}_{4}$ & 146.078 \\
\hline Hexose & $\mathrm{C}_{6} \mathrm{H}_{10} \mathrm{O}_{5}$ & 146.143 \\
\hline Hexosamine & $\mathrm{C}_{6} \mathrm{H}_{11} \mathrm{NO}_{4}$ & 162.053 \\
\hline HexNAc & $\mathrm{C}_{8} \mathrm{H}_{13} \mathrm{NO}_{5}$ & 161.069 \\
\hline Methyl-hexose & $\mathrm{C}_{7} \mathrm{H}_{12} \mathrm{O}_{5}$ & 203.079 \\
\hline Hexuronic-Acid & $\mathrm{C}_{6} \mathrm{H}_{8} \mathrm{O}_{6}$ & 194.079 \\
\hline$N$-Acetyl-neuraminic acid & $\mathrm{C}_{11} \mathrm{H}_{17} \mathrm{NO}_{8}$ & 176.185 \\
\hline$N$-Glycoyl-neuraminic acid & $\mathrm{C}_{11} \mathrm{H}_{17} \mathrm{NO}_{9}$ & 291.095 \\
\hline
\end{tabular}

1) Top figure $=$ monoisotopic mass (based on $\mathrm{C}=12.000000, \mathrm{H}=1.007825, \mathrm{~N}=14.003074, \mathrm{O}=15.994915)$, Lower figure $=$ average mass $(\mathrm{based}$ on $\mathrm{C}=12.011, \mathrm{H}=1.00794, \mathrm{~N}=14.0067, \mathrm{O}=15.9994$.

The masses of the intact glycans can be obtained by addition of the residue masses given above, plus the mass of the terminal group ( $\mathrm{H}_{2} \mathrm{O}$ for an unmodified glycan) 18.011 (monoisotopic) and 18.152 (average), the mass of the adduct and the mass of any reducing-terminal or other derivative. 
Table 3

\begin{tabular}{|c|c|c|}
\hline \multirow{5}{*}{ 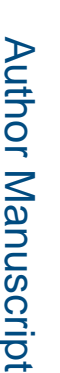 } & \multicolumn{2}{|c|}{ Masses of the $\mathrm{C}_{1}$ fragn } \\
\hline & $m / z$ & Monosaccharide \\
\hline & 179 & Hexose \\
\hline & 220 & HexNAc \\
\hline & 324 & Hex-Fuc \\
\hline
\end{tabular}

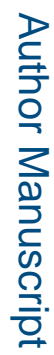

旁

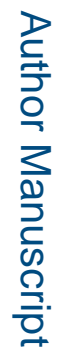

Methods Mol Biol. Author manuscript; available in PMC 2016 April 01. 

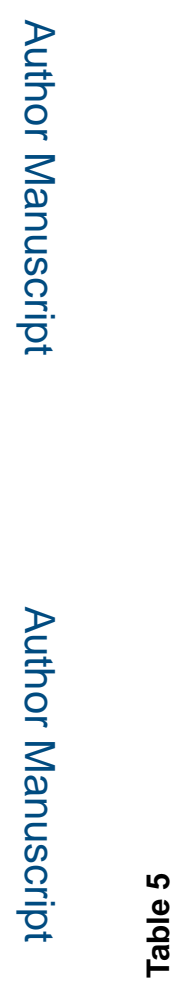

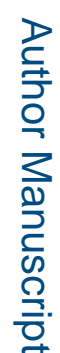

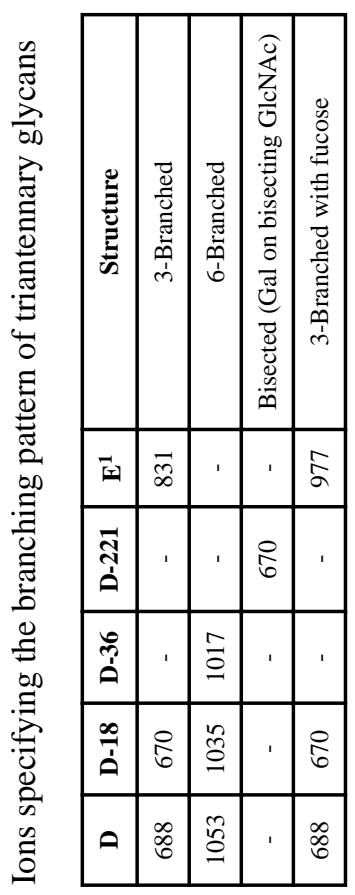

Methods Mol Biol. Author manuscript; available in PMC 2016 April 01. 
Table 6

ᄅํ.

Masses of the (monosaccharides) $+\mathrm{CH}-\mathrm{CH}_{2}-0^{-}$ion specifying the antenna structure

\begin{tabular}{|c|c|}
\hline $\mathrm{m} / \mathrm{z}$ & Composition \\
\hline 62 & HexNAc- $\mathrm{CH}=\mathrm{CH}_{2}-\mathrm{O}^{-}$ \\
\hline 24 & 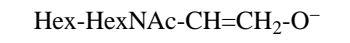 \\
\hline 570 & Hex-HexNAc-Fuc- $\mathrm{CH}=\mathrm{CH}_{2}-\mathrm{O}^{-}$ \\
\hline 465 & 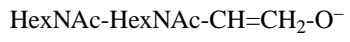 \\
\hline & Hex-HexNAc- $\mathrm{Fuc}_{2}-\mathrm{CH}=\mathrm{CH}_{2}-\mathrm{O}^{-}$ \\
\hline
\end{tabular}

ᄅ

旁

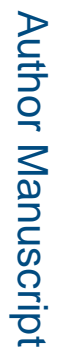

Methods Mol Biol. Author manuscript; available in PMC 2016 April 01. 